\title{
Simultaneous Quantification and Visualization of Titanium Dioxide Nanomaterial Uptake at the Single Cell Level in an In Vitro Model of the Human Small Intestine
}

Thomas Meyer, Tom Venus, Holger Sieg, Linda Böhmert, Birgitta M. Kunz, Benjamin Krause, Pegah Jalili, Kevin Hogeveen, Soizic Chevance, Fabienne Gauffre, Agnes Burel, Harald Jungnickel, Jutta Tentschert, Peter Laux, Andreas Luch, Albert Braeuning, Alfonso Lampen, Valerie Fessard, Jan Meijer, Irina Estrela-Lopis*

T. Meyer, T. Venus, Dr. I. Estrela-Lopis*

Institute of Medical Physics and Biophysics, Leipzig University, Hä telstrasse 16-18, 04107 Leipzig, Germany

E-mail: Irina.Estrela-Lopis@medizin.uni-leipzig.de,Thomas.Meyer@medizin.uni-leipzig.de

Dr. H. Sieg, Dr. L. Böhmert, B. M. Kunz, Dr. A. Braeuning, Prof. Dr. Dr. A. Lampen

German Federal Institute for Risk Assessment, Department of Food Safety, Max-Dohrn-Straße 8-10, 10589 Berlin, Germany

B. Krause, Dr. H. Jungnickel, Dr. J. Tentschert, Dr. P. Laux, Prof. Dr. Dr. A. Luch, German Federal Institute for Risk Assessment, Department of Chemical and Product Safety, MaxDohrn-Straße 8-10, 10589 Berlin, Germany

P. Jalili, Dr. K. Hogeveen, Dr. V. Fessard

ANSES, French Agency for Food, Environmental and Occupational Health Safety, 10B rue Claude Bourgelat, 35306 Fougères, France

Dr. S. Chevance, Dr. F. Gauffre,

Institut des Sciences Chimiques de Rennes, UMR-CMRS 6226, Université de Rennes 1, 35042 Rennes, France

A.Burel, MRIC TEM BIOSIT, Université de Rennes 1, 2av pro Leon Bernard, 35042 Rennes, France

Prof. Dr. J. Meijer

Felix Bloch Institute for Solid State Physics, Leipzig University, Linnéstraße 5, 04103 Leipzig, Germany

PIXE and RBS imaging, dosimetry, uptake, single cell level, nanomaterial

\begin{abstract}
Useful properties render titanium dioxide nanomaterials (NMs) to be one of the most commonly used NMs worldwide. $\mathrm{TiO} 2$ powder is used as food additives (E171), which may contain up to 36\% nanoparticles. Consequently, humans could be exposed to comparatively high amounts of NMs that may induce adverse effects of chronic exposure conditions. Visualization and quantification of cellular NM uptake as well as their interactions with biomolecules within cells are key issues regarding risk assessment. Advanced quantitative imaging tools for NM detection within biological environments are therefore required. A combination of the label-free spatially resolved dosimetric tools, microresolved particle induced X-ray emission and Rutherford backscattering, together with high resolution imaging techniques, such as time-of-flight secondary ion mass spectrometry and transmission electron
\end{abstract}


microscopy, are applied to visualize the cellular translocation pattern of $\mathrm{TiO} 2 \mathrm{NMs}$ and to quantify the NM-load, cellular major, and trace elements in differentiated Caco-2 cells as a function of their surface properties at the single cell level. Internalized NMs are not only able to impair the cellular homeostasis by themselves, but also to induce an intracellular redistribution of metabolically relevant elements such as phosphorus, sulfur, iron, and copper.

\section{Introduction}

In comparison to micro or macro materials, nanomaterials (NMs) exhibit a higher surface/volume ratio and size/shape dependent properties. Their large specific surface area influences the reactivity and awards unique properties to the NMs.[1,2] The large variety of properties made NMs interesting for food and packaging industries.[3-5] Titanium dioxide is one of the most commonly used nanomaterials worldwide.[6, 7] In Europe it is known as the food additive E171,[8] containing up to $36 \% \mathrm{NMs}$.[9] $\mathrm{TiO}_{2}$ is a white, crystalline, odorless, thermically stable and non-flammable substance. Thus it shows no fatigue, is corrosion resistant, biocompatible and absorbs UV light [10]. On the one hand, under non-overloading conditions, it is biologically inactive and physiologically inert with a relative low toxicity.[11, 12] All these properties made it interesting for consumer contact products like in hygiene products such as shampoos and as food additives in e.g. bubble gum, candies, cakes or lip balm.[9] On the other hand, $\mathrm{TiO}_{2} \mathrm{NMs}$ are reported to induce pulmonary inflammation, fibrosis and lung tumor genesis under high dose and/or long exposure time.[13, 14] Taking this into account, titanium was classified as "possibly carcinogenic to humans" by the International Agency for Research in Cancer (IARC).[15] This inconsistency in risk assessment makes titanium dioxide nanoparticles interesting for current research.

Exposure of $\mathrm{TiO}_{2} \mathrm{NMs}$ to humans follows mainly three different routes: inhalation, dermal absorption and oral uptake. Inhalation and dermal routes are certainly the most studied routes of uptake.[16-19] On the contrary, less data are available concerning the uptake and behavior of $\mathrm{TiO}_{2} \mathrm{NMs}$ following the ingestion scenario. Translocation of $\mathrm{TiO}_{2} \mathrm{NMs}$ through the gut and accumulation in liver, spleen, kidney and lungs were observed in in vivo studies.[20-25] Some studies claim that $\mathrm{TiO}_{2}$ translocation was mainly through the small intestine.[20,26] The well characterized Caco-2 cell line as an in vitro model for the human small intestine [27, 28] is commonly used to investigate the response of the gastrointestinal tract to NMs.[11, 29-32] However, the uptake behavior of $\mathrm{TiO}_{2} \mathrm{NMs}$ by intestinal cells and their impact on the epithelium lining as a function of surface properties has been so far poorly investigated.[30, 33]

Adverse responses may depend strongly on the cellular uptake rate of the NMs. Indeed, the cellular or effective dose is considered as a key toxicological endpoint. This is one last link of the chain of several translocation events being a function of physico-chemical and surface properties of NMs. The degree of uptake as well as visualization of translocation patterns of NMs in cells are thus pivotal issues concerning toxicity and risk assessment. However, visualization and quantification of the NM load into the cells is a challenging task. Visualization is mostly performed by fluorescence-based techniques.[34] These techniques require labeling NMs with dye molecules, which may strongly modify the surface properties of NMs. This could likely cause changes in the uptake behavior and cellular response to the NMs or even false positive results.[35] Label-free methods as transmission electron microscopy (TEM),[36, 37] confocal Raman microscopy [38-42] as well as time-of-flight secondary ion mass spectrometry (ToF-SIMS) [43, 44] have been applied for visualization of NMs in biological environment. Dosimetric methods as atomic absorption spectroscopy (AAS) or inductively coupled plasma mass spectrometry (ICP-MS), which were commonly used to quantify NM uptake,[14, $45,46]$ do not offer an access to single cell analysis. Flow cytometry and mass cytometry was recently shown to be useful for semi quantification of cellular NM uptake.[47, 48] Furthermore it is hardly possible for these methods to distinguish between NMs attached to the cellular surface, particles 
internalized into the cell and or just located between cells or within the extracellular fluid.[49] A comparison study of graphene/noble metal nanoparticle uptake in cells between ICP-MS and ion beam microscopy (IBM) based on the analysis of individual cells reveals an overestimation of the cellular uptake by ICP-MS, in particular for cell lines, which do not grow in cell monolayers, like A549 or Gep-G2. .[45] NMs located between the cells or within the extracellular fluid will be just recorded by ICP-MS. On the other hand, comparing studies between IBM and AAS reported similar results on silver NM quantification in monolayers of Caco-2 cells.[46]

The simultaneous quantification and visualization of NMs at single cell level can be conducted by label free IBM techniques [30, 45, 50-56] and synchrotron-based X-ray fluorescent microscopy.[5759] These methods are powerful dosimetric tools to investigate cellular uptake and response mechanisms to NMs based on element analysis. Furthermore, one can gain knowledge about space resolved element distributions in cells. The concentrations of major cellular elements as phosphorus and sulfur, as well as trace elements such as iron, copper and zinc can be evaluated on a single cell level with an accuracy of a few ppm (parts per millions).[53, 60, 61] Combined with information about the cellular concentration of applied nanomaterials and its localization within the cell, a new field of cell analysis emerges.

Element based methods may advance into new fields in the important topic of cellular nanoparticle uptake [57, 62-68] . They enable to differentiate between administered, delivered and the effective or intracellular dose of NMs at a single cell level.[46]

Label-free dosimetric and imaging techniques such as IBM, ToF-SIMS and TEM were applied in this study to visualize and to quantify the $\mathrm{TiO}_{2} \mathrm{NM}$ load across a population of Caco-2 cells. The intracellular localization and NM uptake in differentiated Caco-2 cells were studied as a function of their surface properties at single cell level. Furthermore the co-localization of cellular elements with NMs and the impairment of the cellular homeostasis induced by NMs were investigated as well.

\section{Results and Discussion}

Especially in the field of nanotoxicology, the discussion about the cellular or effective dose is ongoing, as this effective dose is considered as a key toxicological factor. It is considered to represent the true dose measure appropriate for comparing results obtained in different studies. In this work novel imaging and dosimetric techniques were applied to visualize and quantify the NM uptake as a function of surface properties at a single cell level. Two commonly used reference materials for titanium dioxide NMs of similar size and shape were used in this study: The hydrophobic NM103 and the hydrophilic NM104 $\mathrm{TiO}_{2}$ were applied to differentiated Caco-2 cells. The cellular translocation pattern and uptake behavior across cell populations were studied. Moreover, IBM was used to analyze NM induced impairment of cellular homeostasis through quantification of metabolically relevant elements such as $\mathrm{P}, \mathrm{S}, \mathrm{Fe}, \mathrm{Cu}$, and $\mathrm{Zn}$.

\subsection{Characterization of $\mathrm{TiO}_{2} \mathrm{NMs}$}

The general properties of $\mathrm{TiO}_{2} \mathrm{NMs}$ have been characterized extensively. $[69,70]$ In addition, we analyzed in this study the aggregation behavior of these NMs in physiologically relevant media by means of dynamic light scattering (DLS) and nanoparticle tracking analysis (NTA). The Nanogenotox protocol was applied to fabricate $\mathrm{TiO}_{2} \mathrm{NMs}$ with a protein corona on their surface.[71] These protein modified particles were investigated in stock solution ( $0.05 \%$ Bovine serum albumin (BSA) in water) and under cell culture conditions (fetal bovine serum (FBS) containing DMEM cell culture medium). The stability of the NMs in dispersion was studied immediately after the preparation of dispersion $(0 \mathrm{~h})$, after one day and two days of storage.

The results are shown in Figure 1. Similar size distributions and stability behavior were observed for NM103 and NM104. The DLS results provided hydrodynamic diameters ranging from $600 \mathrm{~nm}$ to 
$800 \mathrm{~nm}$ (NM103) and from $380 \mathrm{~nm}$ to $600 \mathrm{~nm}$ (NM104) with large standard errors of the mean (SEM) in stock solution over two days. NTA studies of both NMs exhibited sizes around $150 \mathrm{~nm}$ even after $48 \mathrm{~h}$ in stock solution. Similar NTA results were obtained for all investigated times of storage under cell culture conditions. Here NTA yielded hydrodynamic diameters around $150 \mathrm{~nm}$, while larger values around $250 \mathrm{~nm}$ were measured by DLS. The studied NMs were stable at least over two days after re-suspending in cell culture medium.
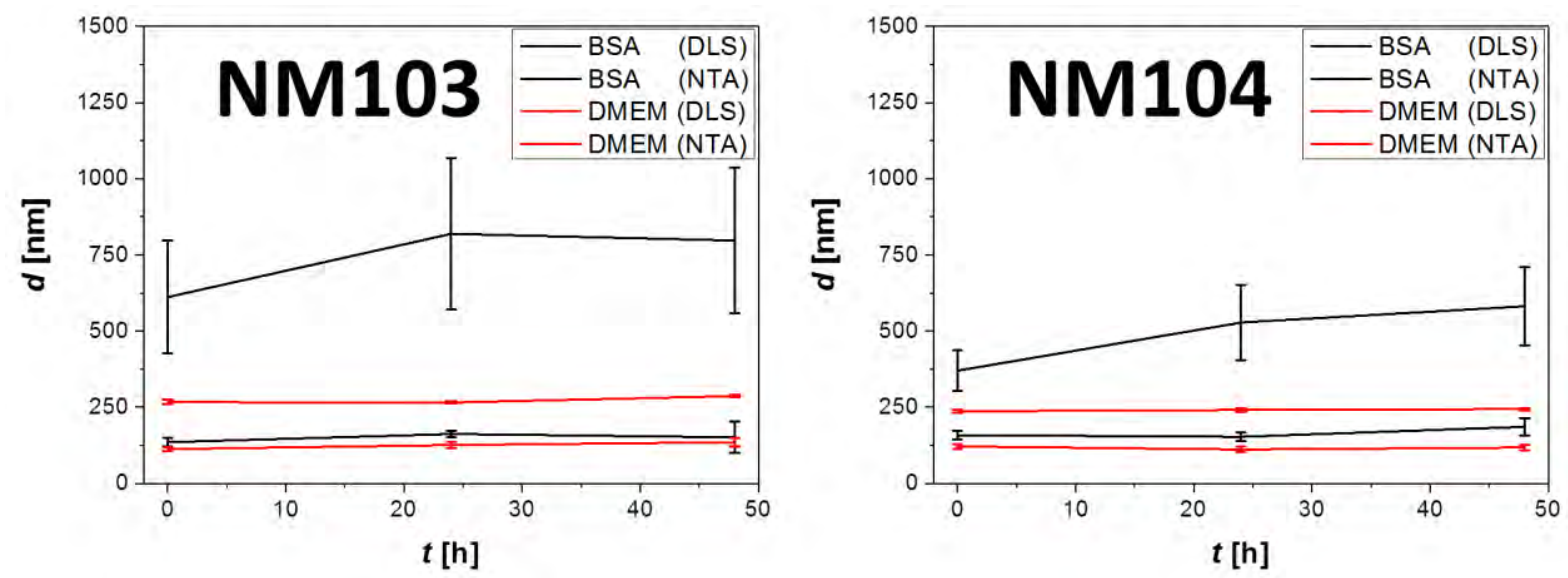

Figure 1. Hydrodynamic diameters of NM103 (left) and NM104 (right) determined by DLS and NTA in Millipore water containing $0.05 \%$ BSA (BSA) and under cell culture conditions, using Dulbecco's Modified Eagle's Medium (DMEM) as a function of time. Error bars display standard errors of the mean.

The two methods, DLS and NTA provided different results concerning the hydrodynamic diameter. A reasonable explanation is that DLS data provide an intensity weighted size distribution of the hydrodynamic diameter. [72-74] The intensity of the scattered light (Rayleigh scattering) correlates with the particle diameter to the power of six. Hence smaller particles are outshined by larger particles especially in samples containing polydisperse particles or particle agglomerates. The polydispersity index of the studied $\mathrm{TiO}_{2} \mathrm{NMs}$ was around of 0.2 in both solutions. Therefore DLS results represent just an upper limit of the size of particles in the sample. On contrary, NTA delivers a number distribution of the hydrodynamic diameter.[75]

The comparison of these two methods allows concluding that the $\mathrm{TiO}_{2}$ particle suspensions contain a small amount of larger aggregates in the aqueous BSA solution. However, the majority of the particles have a size about $150 \mathrm{~nm}$ under cell culture conditions as well as in BSA solution, even after $48 \mathrm{~h}$. Thus, BSA and cell culture medium are appropriate stabilizers for the used $\mathrm{TiO}_{2} \mathrm{NMs.[70]}$

No significant differences in the electrokinetic potential were observed for both NMs in culture media. The Zeta-potential under cell culture conditions was $-16 \pm 1 \mathrm{mV}$ for both investigated materials, NM103 and NM104.

It is known that particles of the same kind but with different surface modifications can develop diverse protein coronae in physiological relevant media.[76] This might affect the cellular uptake of NMs, interaction of NMs with biomolecules and their bioavailability.[77] Therefore, the protein corona compositions of both NMs were investigated after 24 hours of treatment with FBS containing cell culture medium. We found several abundant serum proteins (S 1) such as albumin, $\beta$-actin or diverse metal binding proteins (e.g. tetranectin, albumin) and lipoproteins. The protein corona around both investigated particle species showed frequent similarities, like the enrichment of apolipoprotein A1 and tetranectin and a reduced amount of albumin and other serum proteins. Nevertheless, both coronae showed differences in their compositions as well. While $\beta$-actin was enriched around NM103, its appearance was decreased in the corona of NM104. Plasminogen was strongly enriched only in NM104. Vitamin D binding protein was not detectable on NM103. 
$\beta$-actin plays a major role in the cytoskeleton as well as in endocytotic processes. [78] A link between actin-dependent endocytosis and $\mathrm{TiO}_{2}$ nanomaterials was found in different culture cells.[79-81] Especially the internalization of $\mathrm{TiO}_{2}$ nanoparticle agglomerates was described as actin-dependent.[82] Apolipoprotein A1, which was enriched on both particle species, is associated with cellular uptake processes as well.[83] Plasminogen, as a precursor of plasmin, plays a role in the proteolysis of serum proteins and degradation of fibrin clots. It was already shown, that $\mathrm{TiO}_{2}$ can have an influence on plasminogen activation. $[24,84]$ Therefore knowledge of a composition of the protein corona could be used for prediction of uptake efficiency of NMs as well as of their cellular processing and mode of action.

\subsection{Uptake study of $\mathrm{TiO}_{2}$ at Single Cell Level}

To understand the cellular response to NMs it is essential to determine the distribution pattern and the effective dose of particles taken up by cells. Visualization, internalization and quantification of $\mathrm{TiO}_{2}$ NMs were studied at a single cell level by means of IBM, ToF-SIMS and TEM techniques. Caco-2 cells were exposed to the $\mathrm{TiO}_{2}$ NMs at non-toxic conditions.[85] Two different concentrations (20 and $100 \mu \mathrm{g} \mathrm{ml}^{-1}$, corresponding to 4.7 and $24.4 \mu \mathrm{g} \mathrm{cm}^{-2}$ ) of hydrophobic NM103 or hydrophilic $\mathrm{NM} 104 \mathrm{TiO}_{2}$ at two different time points (12 and $\left.24 \mathrm{~h}\right)$ were chosen for IBM visualization and quantification.

\subsubsection{Visualization of Cellular Translocation of $\mathrm{TiO}_{2}$}

Micro-resolved particle induced X-ray emission ( $\mu$ PIXE) element maps of phosphorus and titanium in control and NM treated differentiated Caco-2 cells are shown in Figure 2. The element maps represent a two dimensional lateral projection of the three dimensional cellular monolayer. The pattern of the phosphorus signal provides a means to identify single cells. The titanium image reveals the distribution of the $\mathrm{TiO}_{2} \mathrm{NMs}$ within cells. 


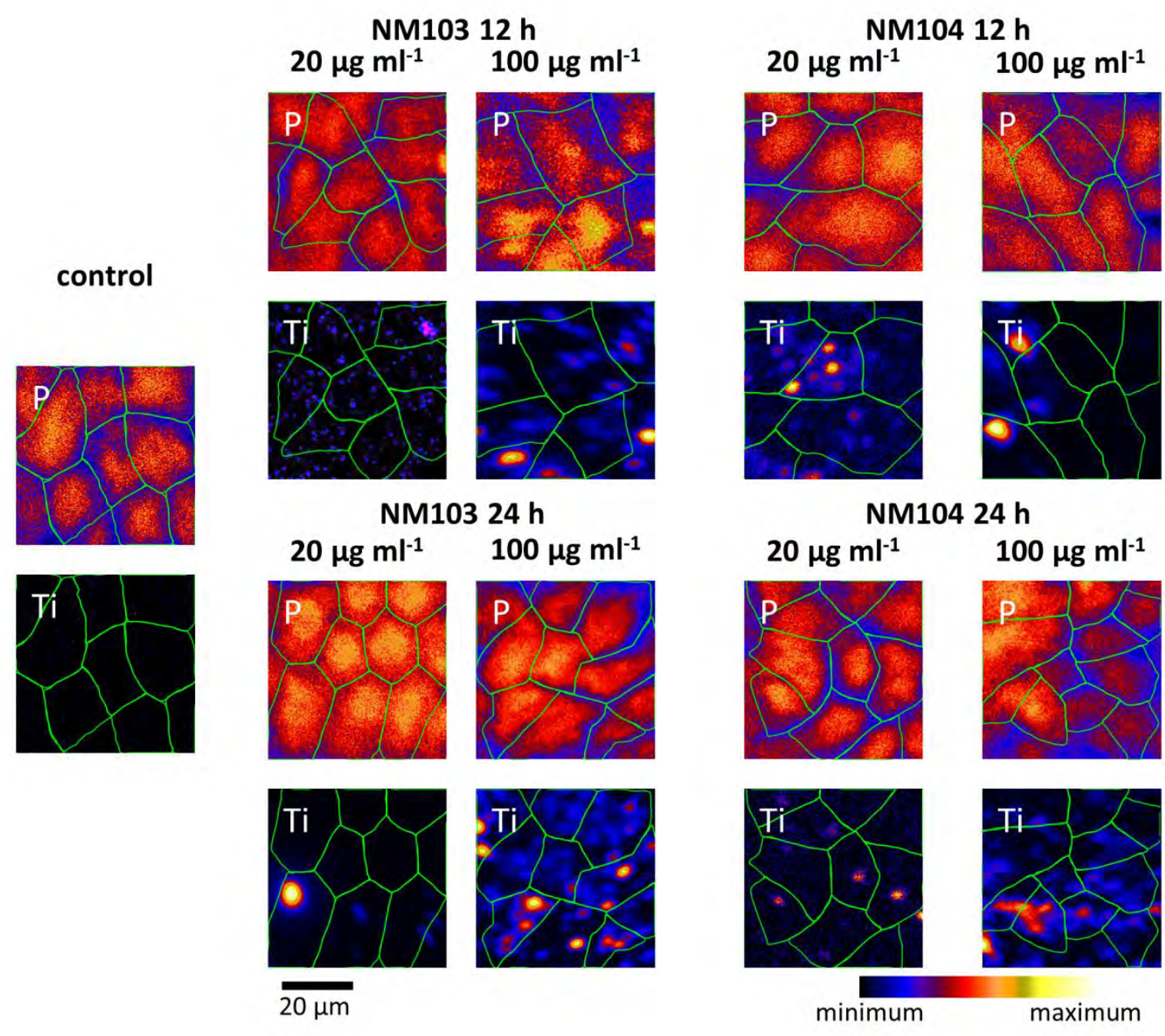

Figure 2. $\mu$ PIXE element maps of differentiated Caco-2 cells. Phosphorus and titanium maps are shown for control cells and cells exposed to NM103 and NM104. The lateral images were recorded at the different exposure scenarios, namely 20 and $100 \mu \mathrm{g} \mathrm{ml}^{-1}$ over 12 and $24 \mathrm{~h}$ exposure time. All images display an area of $50 \times 50 \mu \mathrm{m}^{2}$.

Phosphorus is an omnipresent element inside cells. It is a part of the phospholipids of the cell membrane and it is essential for ATP, which regulates the energy budget of the cell. Furthermore it is present in the phosphate backbone of nucleic acids. A higher local concentration of phosphorus represents the cellular nucleus due to the DNA phosphate backbone. On the basis of the phosphorus signal on alignment with other cellular elements one can distinguish between single cells in a confluent cellular monolayer. The mutual boundaries between adjacent cells are given by a minimum of the phosphorus signal. This made single cell analysis of differentiated Caco-2 cells possible, except when two cells overlay.

Figure 2 reveals a strongly inhomogeneous titanium distribution both through the cell population and

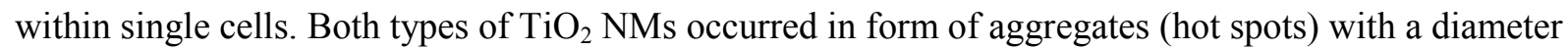
up to $11 \mu \mathrm{m}$. The size distribution of $\mathrm{TiO}_{2}$ aggregates within the cells in the PIXE maps were analyzed by Image-J software. The histograms reveal the area distribution of single $\mathrm{TiO}_{2}$ aggregates, expressed in $\mu \mathrm{m}^{2}$, within the cell exposed to two types of $\mathrm{TiO}_{2} \mathrm{NMs}(\mathbf{S} 2)$. The size of aggregates was remarkably higher in the cells treated with NM103 compared to NM104 NMs at different exposure scenarios. Furthermore, the number of aggregates per cell was higher for NM103 NMs as well. The number and size of aggregates within the cells are measures of the uptake rate of NMs. NM103 are 
prone to form larger aggregates than NM104 NMs within the cells. The large aggregates might impair the mechanical properties of cells.[86]

TEM and ToF-SIMs experiments were carried out to more precisely characterize the NM localization within the cell $(\mathbf{S ~ 3 , S ~ 4 ) . ~ B o t h ~ m e t h o d s ~ s h o w ~ t h e ~ i n t e r n a l i z a t i o n ~ o f ~ h y d r o p h o b i c ~ a s ~ w e l l ~ a s ~ h y d r o p h i l i c ~}$ NMs within Caco-2 cells. TEM images visualized $\mathrm{TiO}_{2} \mathrm{NMs}$ as small spots inside vesicles, which resemble endosomes or lysosomes. The NMs were preferentially located in the top face of the cells. Localization of NMs in close vicinity of the cell membrane was also found by ToF-SIMs. Furthermore, NMs, especially NM103, were agglomerated as large dense clusters inside Caco-2 cells. This correlates well with the IBM data, which demonstrated large NM 103 agglomerates with a mean area of approximately $20 \mu \mathrm{m}^{2}$ within exposed cells (Fig. 2 and S 2).

\subsubsection{Internalization of $\mathrm{TiO}_{2}$ in $\mathrm{Caco}-2$ Cells}

Nanomaterials internalized into cells could interact directly with biomolecules and interfere with different biochemical processes. Therefore, it is of major importance to distinguish between internalized nanomaterials and nanomaterials only attached to the cell surface. Micro-resolved Rutherford backscattering spectroscopy ( $\mu$ RBS) offers the possibility to investigate the state of internalization and to determine the distribution of NMs inside the cells in z-direction. Caco-2 cells were exposed to NM 103 and NM104 and RBS spectra referring to single cells were extracted. Backscattered protons lose energy due to elastic collisions between the high energetic $\mathrm{H}^{+}$projectiles $(E=2300 \mathrm{keV})$ and the stationary target. The energy of backscattered protons from titanium in a thin film is expected at about $2115 \mathrm{keV}$. However, an energy loss of backscattered protons from Ti atoms down to $2100 \mathrm{keV}$ was observed in $\mathrm{TiO}_{2} \mathrm{NM}$ exposed Caco-2 cells (Figure 3). The intensity distribution of backscattered protons as a function of energy and their energy loss contain information about the distribution of NMs along the $\mathrm{Z}$ axis of the cell. Protons hit and penetrate into the cell undergo numerous interactions with target electrons and nuclei resulting in a loss of energy. Backscattering from titanium located at a certain depth in the cell thus occurs with lower "effective" incident energy. 

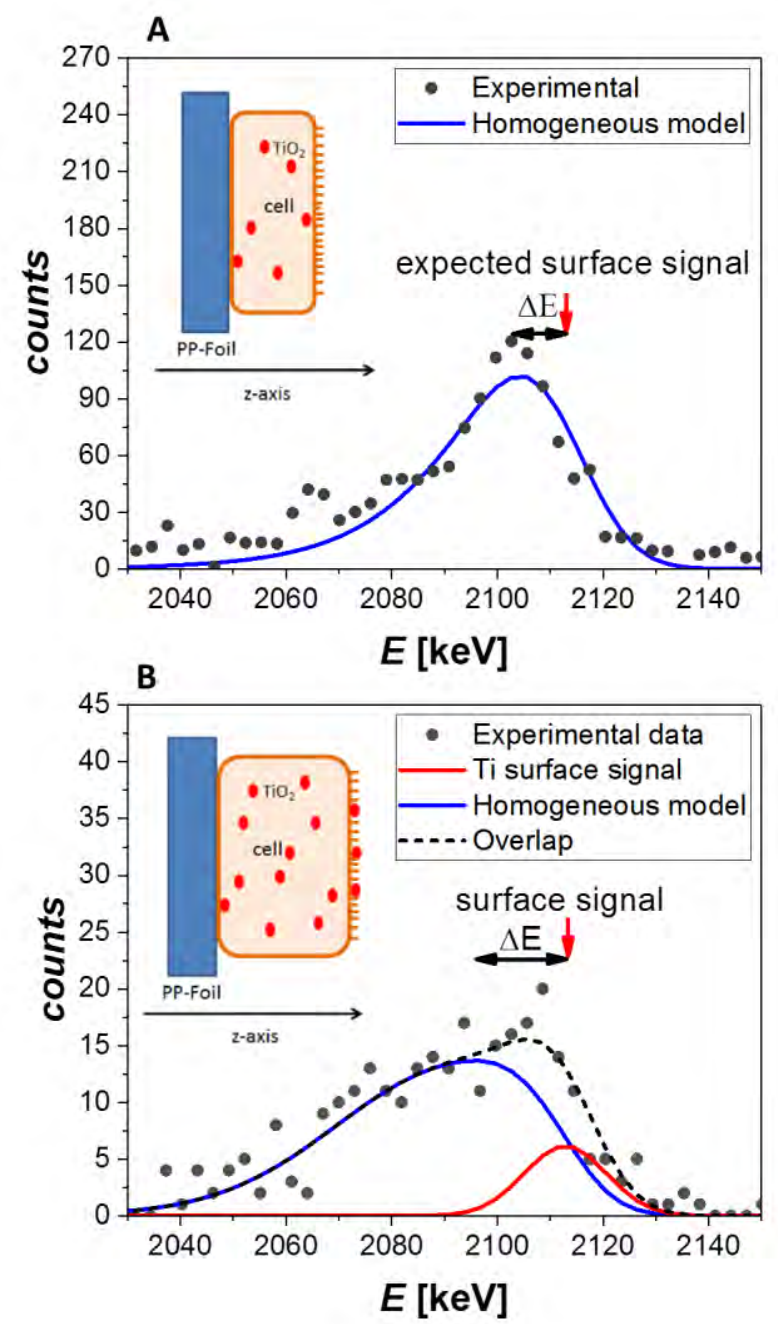

Figure 3. Example of RBS spectra extracted from two exposed cells. A: $\mathrm{TiO}_{2} \mathrm{NMs}$ were internalized and homogeneously distributed along z-axis; $\mathrm{B}: \mathrm{TiO}_{2} \mathrm{NMs}$ were internalized as well as associated to the cell surface. The cartoons demonstrate the applied models to fit the RBS experimental data of individual cells.

To assess the degree of internalization a threshold of ca. $5 \mathrm{keV}$, which reflects a depth of around $300 \mathrm{~nm}$, was assumed. This refers to the minimum difference of the peak maxima originated from titanium attached to the surface and internalized titanium. The overall titanium peak was then fitted as an overlap between surface associated and internalized titanium. The contribution of the smaller of the two peaks to the total area of the titanium peak had to be at least $10 \%$ to be taken into consideration.

Figure 3 A shows the RBS spectrum summed from a single Caco-2 cell exposed to titanium dioxide. The energy range of protons scattered from Ti atom is shown to determine the internalization of the nanomaterials. The penetration depth of NMs within the cell, the detector resolution and cell roughness were taken into account for the analysis of energy loss and fitting of RBS spectra. The roughness of Caco-2 cells was considered for the analysis. It is mainly due to microvilli on the apical side. For the fit a homogeneous model (Figure 3 cartoons) was applied, which is a good working approach to simulate the averaged lateral distribution of Ti along the z-axis within individual cells. The dots and the blue line represent the recorded data and the fit of the data. The red arrow indicates the maximum of the expected peak from surface associated titanium dioxide. In the provided example a significant energy shift was observed.

Figure $3 \mathrm{~B}$ shows another example of a Caco-2 cell exposed to $\mathrm{TiO}_{2}$. The blue line represents the homogeneous model. The red line represents the fit to the surface model taking into account only 
surface associated titanium. The black dashed line exhibits the fit as an overlap of both models. In this case, titanium was found internalized as well as bound to the cell surface. The contribution of the surface signal to the total peak area is around $15 \%$, while $85 \%$ of the titanium signal originated from internalized titanium.

Table 1. Results of the internalization studies of $\mathrm{Caco}-2$ cells exposed to titanium dioxide NM103.

\begin{tabular}{ll}
\hline Internalization status & $\begin{array}{l}\text { Amount of cells } \\
{[\%]}\end{array}$ \\
\hline Surface & 0 \\
Surface+ Internalized & 8 \\
Internalized & 92 \\
\hline
\end{tabular}

Because of a low RBS cross section of titanium only cells with high titanium content were selected for internalization analysis. 26 cells exposed to NM103 were investigated in the same way as in the shown examples. Table 1 summarizes the internalization study. Cells, where the significant amount of NMs was associated with the cell surface were not found. In case of cells exposed to NM103 around $92 \%$ of the cells show a complete internalization. $8 \%$ of the investigated cells exhibit titanium on the cellular surface as well as internalized titanium. NM104 exhibits similar internalization tendencies. This is in good agreement with the ToF-SIMS and TEM results, were the main fraction of the NMs were observed as internalized agglomerates.

A few studies reported the location of $\mathrm{TiO}_{2} \mathrm{NMs}$ between cells entrapped between microvilli or located in cytoplasmic vesicles.[30, 87] It was assumed that NMs were mainly transported via the paracellular route. Paracellular uptake of $\mathrm{TiO}_{2} \mathrm{NMs}$ was observed in several models of the small intestine (using Caco-2, Caco-2/Raji-B and Caco-2/Ht29-MTX co-culture) due to an impairment of cell junctions. $[30,88]$ It is also known that membrane invagination and consequently endocytosis of microvilli membrane is sterically prevented. This can be understood as a protective mechanism of the organism to minimize access of pathogens via the gut lumen.[89] Nevertheless, in this study $92 \%$ of $\mathrm{TiO}_{2} \mathrm{NMs}$ penetrated the cellular membrane and were found partly in endocytic vesicles. This might have several reasons. It could be explained by apical endocytosis from micro crypt areas between neighboring microvilli.[89] Furthermore it was shown that $\mathrm{TiO}_{2}$ induces morphological changes and destructions of the cellular microvilli surface.[90] This disorganization of the brush border could open a gate for endocytotic uptake. The $\beta$-actin enrichment in the protein corona of the hydrophobic NM103 (FIGURE S1) could also accelerate endocytotic uptake additionally.

\subsubsection{Quantification of NM Uptake}

Quantification of NM uptake as well as cellular element concentrations were performed by analysis of RBS and PIXE spectra extracted from single cells. Figure 4 shows PIXE element maps of phosphorus, sulfur and titanium in case of Caco-2 control cells and Caco-2 cells exposed to $20 \mu \mathrm{g} \mathrm{ml}^{-1}$ NM103 over a time of $24 \mathrm{~h}$. The green line determines the region of interest (ROI). PIXE and RBS spectra included in the ROI were summed up and are shown in Figure 4. 

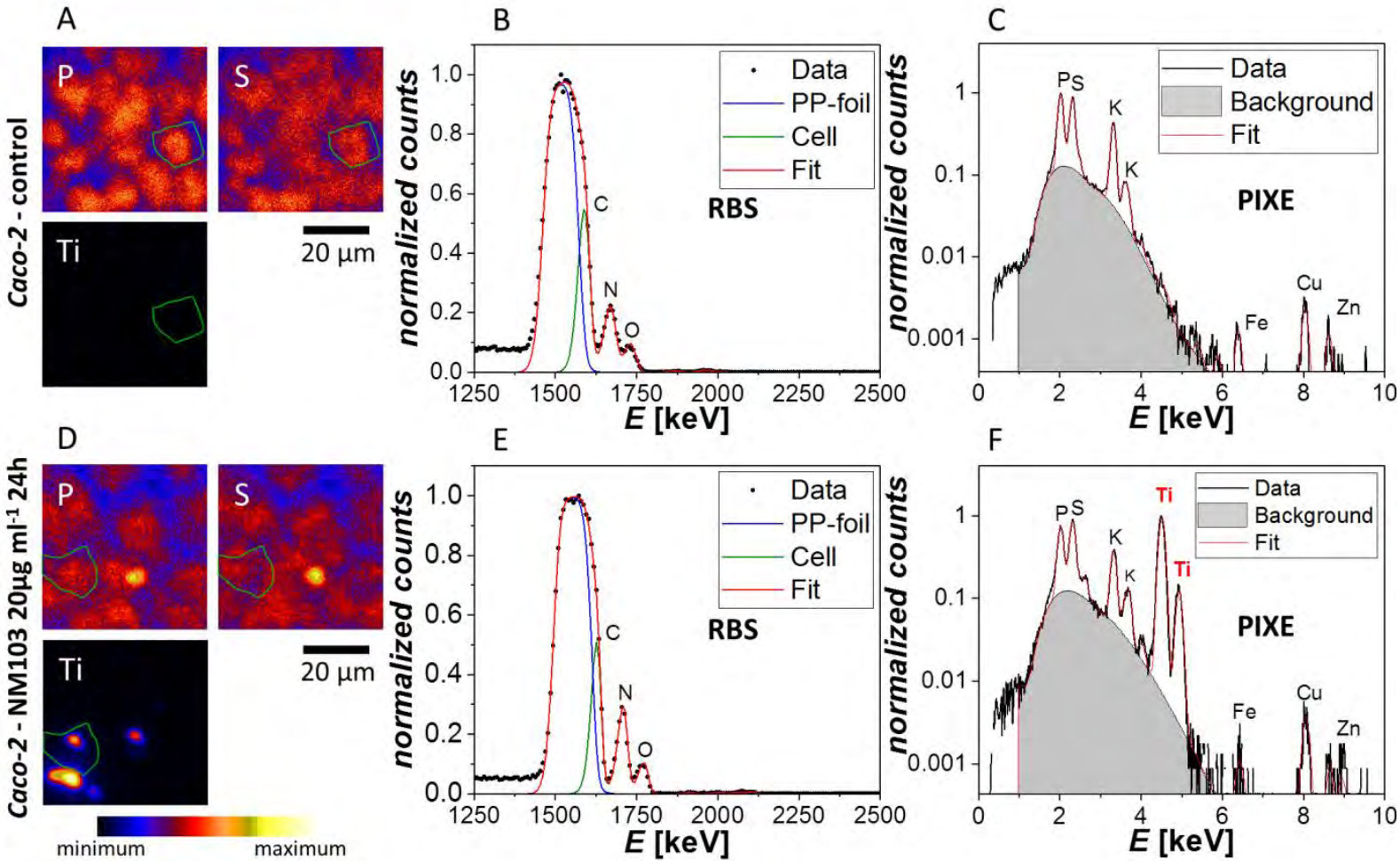

Figure 4. $\mu$ PIXE element maps of Caco-2 control cells (A) versus Caco-2 cells exposed to NM103 $\left(20 \mu \mathrm{g} \mathrm{ml}^{-1}\right.$; $24 \mathrm{~h}$ ) (D). The images reveal element distributions of phosphorus, sulfur and titanium. Areas of $50 \times 50 \mu \mathrm{m}^{2}$ were mapped. RBS (B, E) and PIXE (C, F) spectra were extracted from one single cell framed by green line.

The dots in the RBS spectra display the recorded experimental data. The fit (red line) is an overlay of the cellular layer (green line) and the polypropylene foil (PP-foil) (blue line) on which the cell grew. The cellular matrix composition, especially the carbon, nitrogen and oxygen content and the thickness of the individual cells were calculated from RBS spectra. Furthermore, the accumulated charge of the ROI, which reflects the number of protons interacting with a single cell, was recomputed.

The PIXE spectra shows characteristic x-ray lines for different element specific energy transitions, e.g. $\mathrm{P}-K_{\alpha}$ at $2.01 \mathrm{keV}$ or $\mathrm{Ti}-K_{\alpha}$ and $\mathrm{Ti}-K_{\beta}$ at 4.51 and $4.93 \mathrm{keV}$. One can see typical lines for cellular elements $\mathrm{P}, \mathrm{S}, \mathrm{K}, \mathrm{Fe}, \mathrm{Cu}$ and $\mathrm{Zn}$ as well as Ti in case of exposed cells (Figure $4 \mathrm{~F}$ ). The gray colored area displays the fit of the background originating from the bremsstrahlung. The red line represents the fit of the PIXE spectrum. The areas under the PIXE peaks displayed in Figure $4 \mathrm{C}$ and $\mathrm{F}$ are proportional to the concentration of the different elements. Using the information gathered out of the RBS data, such as matrix composition, thickness and accumulated charge derived from individual cells, as well as the element specific cross sections and the detector efficiency, the area density of the studied elements, e.g. Ti, expressed in $\mathrm{ng} / \mathrm{cm}^{2}$ can be calculated from the PIXE spectrum .[50] Briefly, the RBS spectrum of single cells provides the atom composition of the major cellular elements and the number of atoms $/ \mathrm{cm}^{2}$. It allows calculating the dry mass of the cell per area, given in $\mathrm{mg} / \mathrm{cm}^{2}$. Since the area of the dried individual cells is known the total mass of individual cells can be calculated if required. PIXE element quantification is an approved and calibrated[46] method to determine element concentrations in biological matters with an atomic number beyond $\mathrm{Mg}$. For verification of element quantification element standards of Astimex Standards Ldt (Serial EPX1 SPEC 25-53+FC) were measured and compared to manufacturer's data (S 5). The ratio between the measured and the certified concentration was used to validate accuracy of the method. All investigated elements fall within a $10 \%$ tolerance range. 
Figure 5 shows the cellular Ti concentrations calculated at a single cell level as described above. The values represent the mean values of the element amount in $\mu \mathrm{g}$ per $\mathrm{g}$ dried sample mass [ppm] calculated for each single cell separately. Mean values were calculated from ensembles ranging from 32 up to 70 single cells contributed from two independent technical replications.

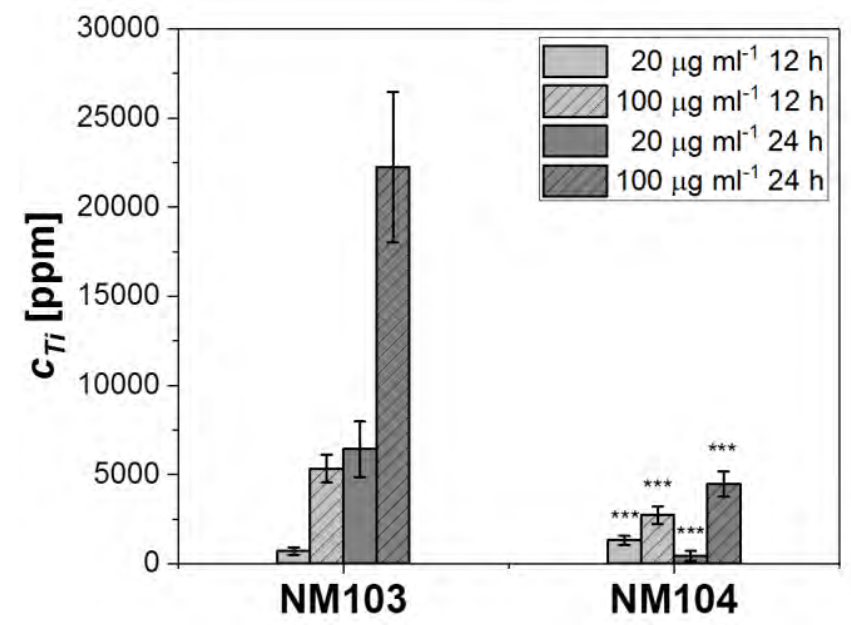

Figure 5. Quantification of NM uptake in Caco-2 cells exposed to NM103 or NM104. Significance levels were determined by comparing NM103 and NM104 regarding their exposure conditions. ${ }^{*} \mathrm{P}<0.05 ;{ }^{*} \mathrm{P}<0.01$; $* * * \mathrm{P}<0.001$.

The cellular NM-load (Figure 5) depends strongly on the exposure conditions as well as on the surface modification of the particle. The hydrophobic NM103 reached a significantly higher cellular concentration compared to the hydrophilic NM104. The cellular load was four times higher for NM103 compared to NM104 at exposure concentration of $100 \mu \mathrm{g} \mathrm{ml}^{-1}$ over $24 \mathrm{~h}$. The maximum value of uptake efficiency, expressed in the ratio of effective to administered doses, was about $14 \%$ and $4 \%$ for hydrophobic and hydrophilic $\mathrm{TiO}_{2} \mathrm{NMs}$, respectively. The efficiency of cellular uptake was closely connected with the protein corona composition for the two used NMs. The hydrophobic NM103 showed highly increased $\beta$-actin amount, which is known to be involved in endocytotic processes [78] and brought in connection with NM uptake.[79]

Furthermore, the uptake behavior for both NMs exhibits different patterns. In case of cells exposed to $20 \mu \mathrm{g} \mathrm{ml}^{-1}$ hydrophobic $\mathrm{TiO}_{2}$ the titanium amount was drastically increased by a factor of around 10 from 12 to $24 \mathrm{~h}$ exposure time (Figure 5). In case of hydrophilic $\mathrm{TiO}_{2}$ the level of Ti concentration was decreased by a factor of three after $24 \mathrm{~h}$ compared to $12 \mathrm{~h}$ (Figure 5). Even at the highest applied concentration, $100 \mu \mathrm{g} \mathrm{ml}^{-1}$, the uptake of hydrophilic $\mathrm{TiO}_{2}$ was hardy altered over 24 hours. 


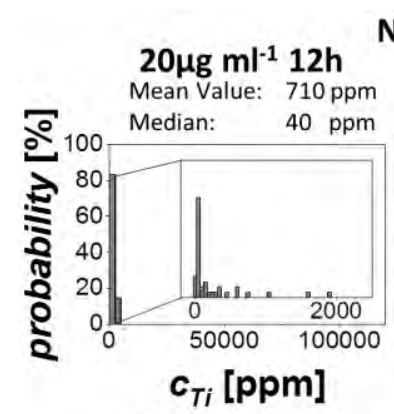

\section{NM103}
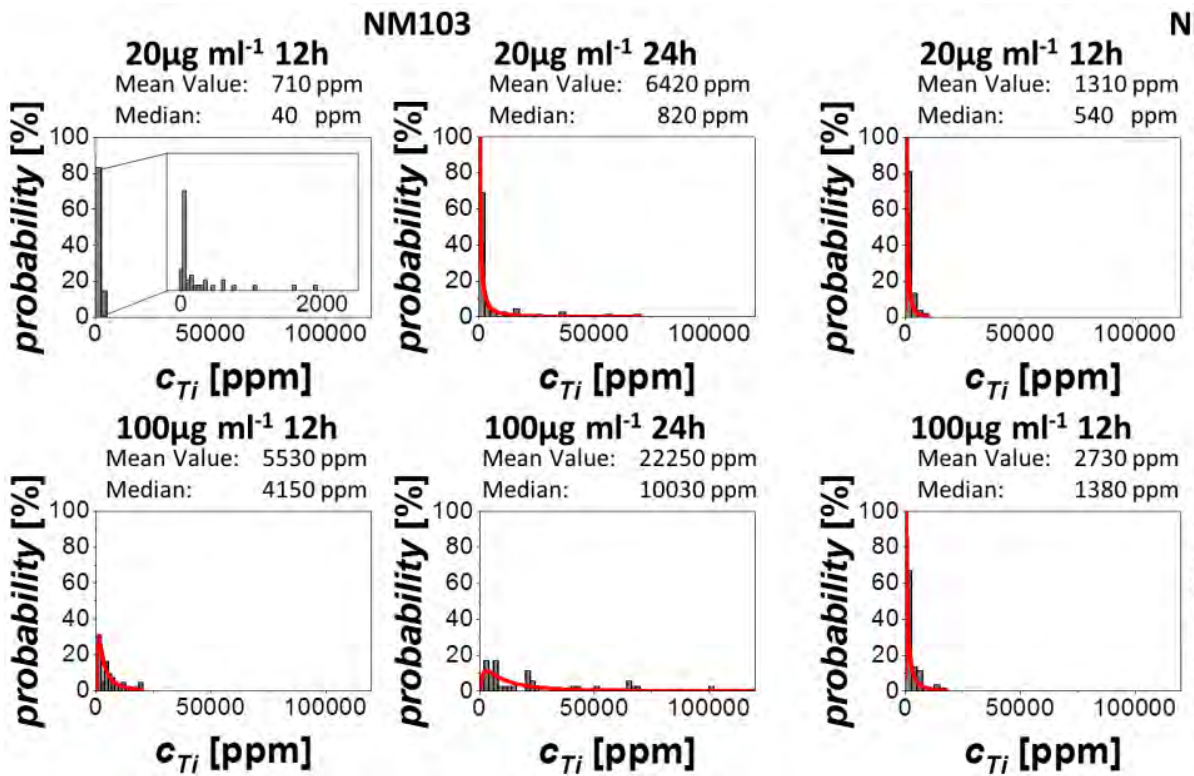

NM104
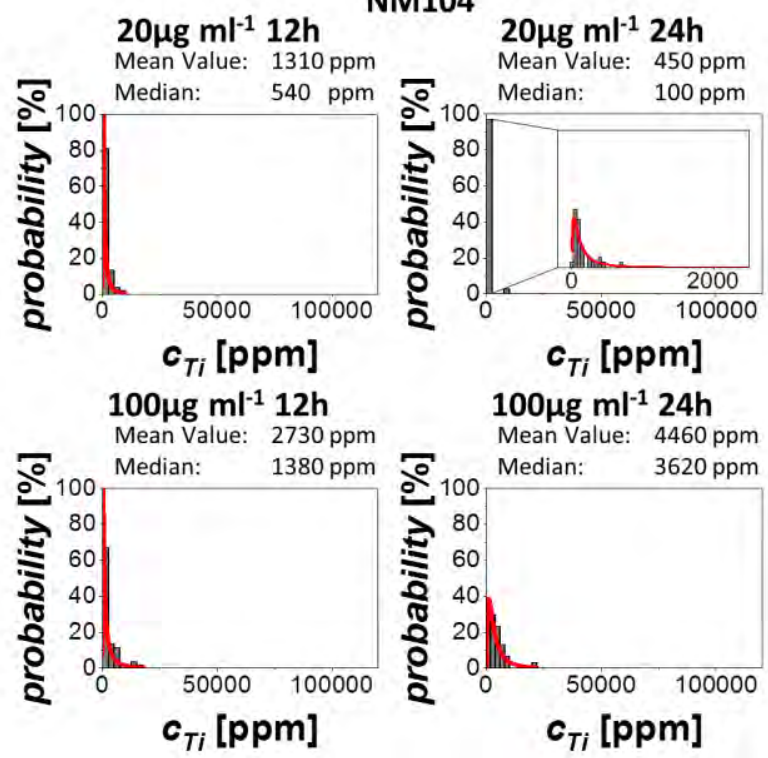

Figure 6. Intracellular titanium load $\left(\mathrm{c}_{\mathrm{Ti}}\right)$ across a population of Caco-2 cells for the different exposure scenarios. The red line displays a log-normal fit of the distribution.

The cellular Ti load across cell populations under different exposure scenarios are shown in Figure 6. Histograms of cellular Ti content were generated by analyzing different individual cells exposed to NMs. The median values were found to be remarkably smaller than the mean concentrations of titanium in the cells. Figure 6 exhibits rather inhomogeneous distributions of NM content across populations of Caco-2 cells. A closer look at titanium load histograms reveals non-Gaussian distributions of Ti content over the cell populations. Asymmetrical distributions, which are close to log-normal ones, were observed. It is known that the log-normal distribution describes the content of biomolecules across a cell population.[91, 92] It has been discussed and assumed that determinates of gene expression capacity, which drive the endocytosis, are log-normal distributed. Therefore, they could lead to log-normal distribution of NM content over a cell population, when the endocytotic pathway is assumed.[57, 93] On the basis of the population study (Figure 6) it could be suggested that one of the major mechanisms of $\mathrm{TiO}_{2}$ uptake was endocytosis. This correlates to TEM analysis, showing NMs inside endocytic vesicles (S 3).

The analysis of cellular Ti load across a population of cells further reveals that some cells take up a very high amount of titanium. This effect was mainly observed in cells exposed over 24 hours to the hydrophobic $\mathrm{TiO}_{2}$ NM103 (Figure 5). For the definition of high-load cells a threshold of cellular NM concentration was set. Loads above 5 times higher than the median value were considered as highload. About $30 \%$ and $17 \%$ of high-load cells were seen for applied concentrations of $20 \mu \mathrm{g} \mathrm{ml}^{-1}$ and $100 \mu \mathrm{g} \mathrm{ml}^{-1}$, respectively, after 24 hours of exposure in case of hydrophobic NMs. The formation of high-load cells was not observed in such extent in case of hydrophilic $\mathrm{TiO}_{2}$. Here only around $4 \%$ of high-load cells were found under similar conditions. The increased number of cells with a high amount of Ti-concentration reflects consequently the uptake of large agglomerates. Analysis of TEM and PIXE images of cellular distribution patterns of the hydrophobic $\mathrm{TiO}_{2} \mathrm{NMs}_{\text {(Figure 2, }} 2$ and S 3) are supporting this assumption. NM aggregates up to a size of ca. $100 \mu \mathrm{m}^{2}$ were detected in form of hot spots inside of high-load cells at a larger extent for hydrophobic $\mathrm{TiO}_{2} \mathrm{NMs}_{\text {(S 2). }}$

The use of mean values of cellular uptake is widespread in dosimetric methods as atomic absorption spectroscopy or ICP-MS. On one side this value delivers important statistically relevant information about uptake rate. On the other side the mean value is insensitive to outliners, such as high-load cells. However, these cells are of special interest from a toxicological point of view. They could lead to local damaging and impairment on organismic level and hence to long-term adverse effects. Therefore, it is 
of major interest to perform analysis at single cell level. It provides unique information about real distribution of cellular NM content across cell population revealing the presence of high load cells as well as hot spots within cells.

\subsection{NM Induced Dysregulation of Cellular Homeostasis}

The knowledge of cellular concentrations of metabolically relevant elements allows gaining insights in the cellular response induced by hydrophobic and hydrophilic titanium dioxide. The results are displayed in Figure 7 and S 6. In Figure 7 the element concentrations [ppm] of Caco-2 cells were determined for major, phosphorus and sulfur, and trace elements, iron, copper and zinc. In order to consider possible impact of NMs on dried mass of exposed cells, the total content of intrinsic cellular elements in single cells was calculated taking into account area of each individual cell (S 6). All data represent the mean value over the investigated population. Figure 7 and S 6, where element content was expressed in ppm and $\mathrm{pg} / \mathrm{cell}$, exhibit similar tendencies regarding the cellular element homeostasis.

\section{NM103}
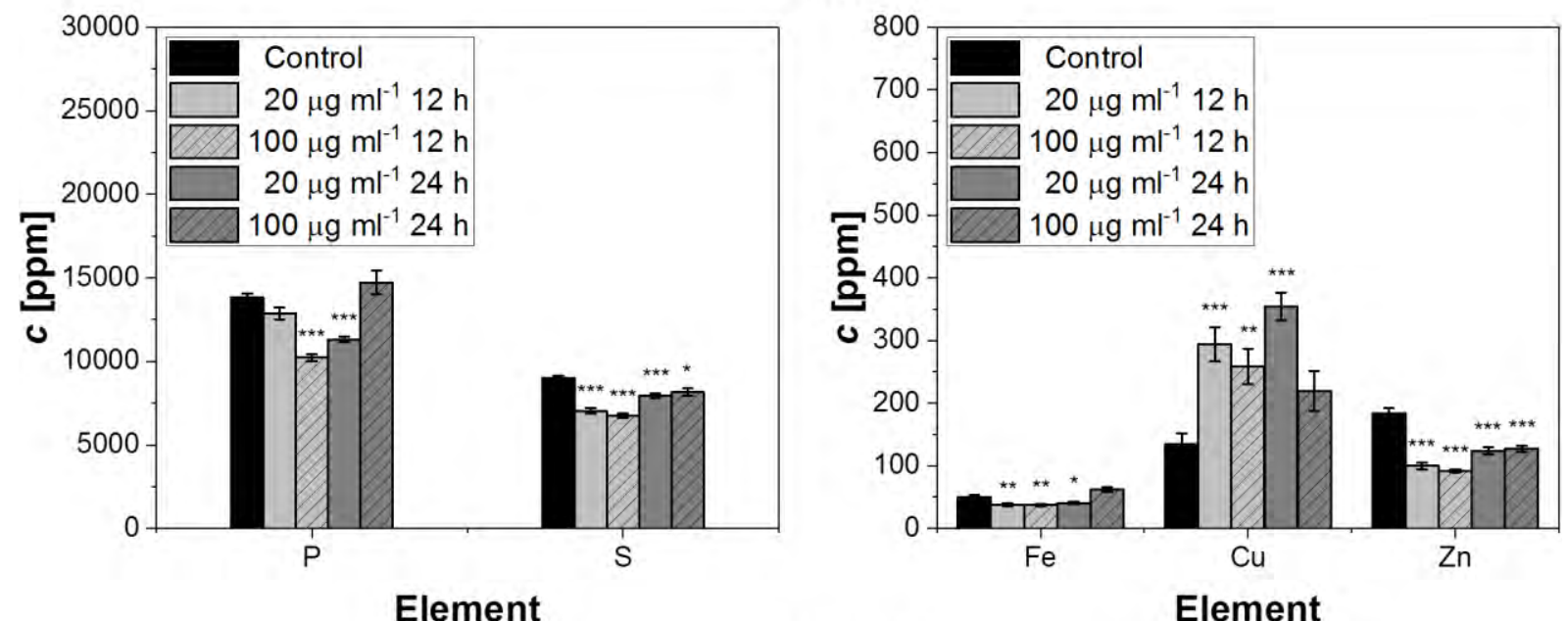

NM104
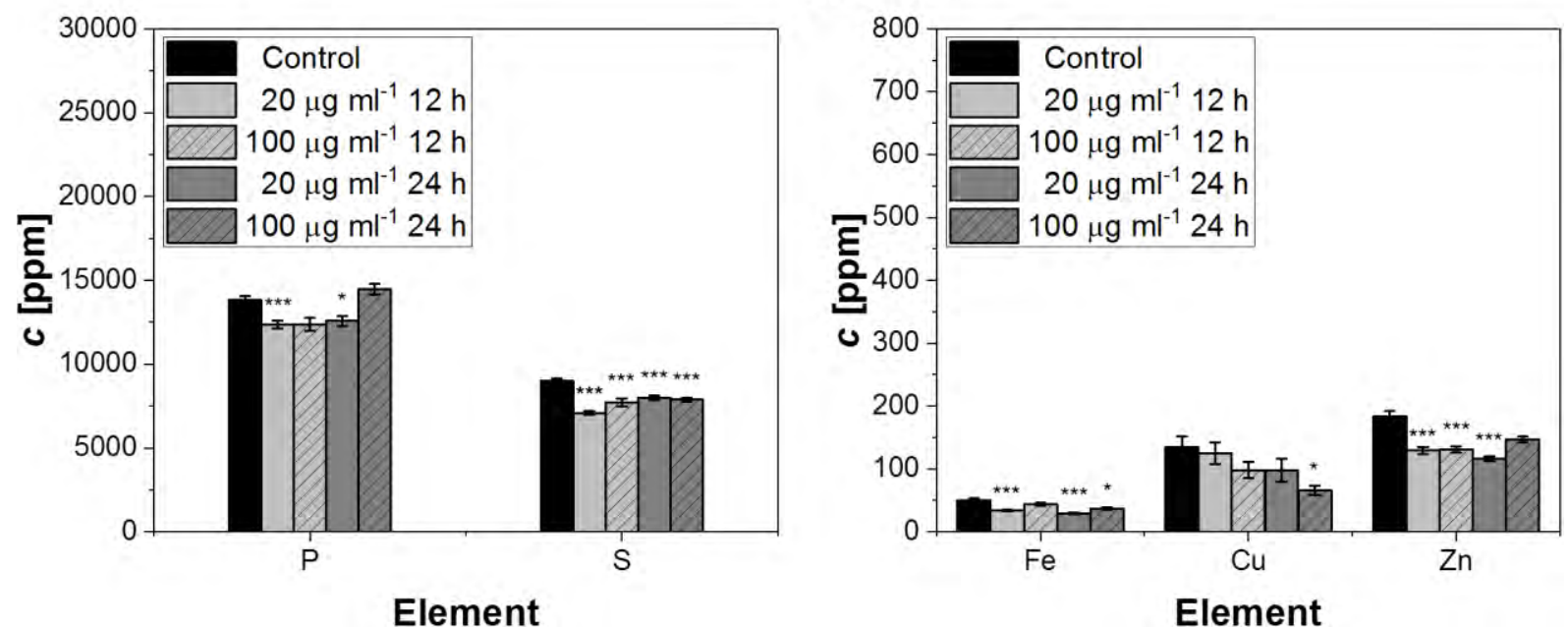

Figure 7. Quantification of cellular element concentrations in Caco-2 cells exposed to hydrophobic NM103 or hydrophilic NM104 under different conditions. The determined significance levels refer to the control cells. $* \mathrm{P}<0.05 ; * * \mathrm{P}<0.01 ; * * * \mathrm{P}<0.001$.

For both NMs, as hydrophobic and hydrophilic, a significant decrease of phosphorus, sulfur, iron and zinc was observed in NM treated cells under almost all exposure conditions. The extent of decrease of these elements was neither exposure nor dose dependent. The presence of intracellular NMs probably 
triggers an impairment of the element homeostasis. The hydrophobic NM103, which was taken up more efficiently, affected the cellular Zn-content more strongly. The zinc concentration was up to two fold decreased compared to control cells. On the other hand, the hydrophilic $\mathrm{TiO}_{2} \mathrm{NM} 104$ affected more efficiently the Fe-content which was found to be up to two times lower compared to control cells.

The NM-induced impairment of $\mathrm{Cu}$ homeostasis exhibits a different behavior between the hydrophobic and the hydrophilic $\mathrm{TiO}_{2}$ NMs. The hydrophobic NM103 caused an increase of the cellular copper up to nearly $280 \%$ of the intrinsic concentration, while the hydrophilic NM104 induced a decrease of copper concentration down to $50 \%$. It may be assumed that the remarkably different response pattern of intrinsic iron, zinc and copper to NMs could be related to the polar properties of NM surface and/or the different protein corona compositions.

The regulation and maintenance of homeostasis at organisms and on cellular levels play a key role in cell biology. An impairment of homeostasis of metabolically relevant elements has been observed in several diseased states.[94] The dysregulation of $\mathrm{Fe}, \mathrm{Cu}$ and $\mathrm{Zn}$ plays an important role in neurodegenerative diseases as Alzheimer's disease, Parkinson's disease and prion disease.[95] The iron cellular concentration in varicose vein was found to be an indicator of the progression of chronic venous disease.[96] Furthermore, iron accumulation in colon epithelial cells was found to be related to colorectal cancer.[97-99] The elevated Fe content was suggested to increase the risk of age-related diseases.[100-102] An inhibited iron uptake can lead to iron deficiency and anemia.[103] A Copper metabolism disorder is connected to several diseases, e.g. Menkes and Wilson's diseases. It was shown that copper levels were significantly elevated in Alzheimer's disease patients.[104] Iron and copper belongs to redox active metals which are able to produce reactive oxygen species (ROS) through Fenton reaction.[105] Their dysregulation may results in the adverse effects on cell and whole organism level.

The role of zinc in cellular processes is well understood. It is known for its regulation of cytokines as mediator in inflammatory processes [106] and its influence on the permeability of Caco-2 cells monolayers.[107] Impairment of $\mathrm{Zn}$ homeostasis is connected to several diseases, e.g. atherosclerosis and the development of diabetes mellitus $[106,108]$ as well as inflammatory bowel disease and gastric mucosa inflammation.[109, 110] It was shown that titanium dioxide NMs with a diameter of $30 \mathrm{~nm}$ led to an decreased iron and zinc transport in cells.[111] It was suggested that the transport mechanisms were disturbed by $\mathrm{TiO}_{2} \mathrm{NM}$ ingestion.[111] This goes along with our findings, where decreased zinc and iron cellular concentrations were observed, even under nontoxic exposure

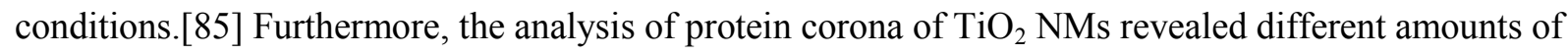
metal binding proteins (albumin, iron export ABC transporter ATPase, ovotransferrin and tetranectin) and membrane transport proteins (solute carrier family) associated with NM surface (S 1). Therefore, it is assessed that taken up $\mathrm{TiO}_{2} \mathrm{NMs}$ have the capacity for binding of metal ions at their surface and for immobilization of the transport proteins intracellularly. These could lead to impairment of the element homeostasis. Due to the ubiquitous role of metal elements for cellular functions, a significant change in the household of these elements could lead to incalculable long term effects on the cell level as well as on the organism level. Long term effects of $\mathrm{TiO}_{2} \mathrm{NMs}$ and E171 on rats were already shown.[112] On the one hand, it was claimed that an acute exposure of one week to rats led to an accumulation of $\mathrm{TiO}_{2}$ in peyer's patches, but did not induce instestinal inflammation. On the other hand, 100 days of treatment with $\mathrm{TiO}_{2} \mathrm{NMs}$ promoted colon micro-inflammation and stimulated the growth of deviant crypt foci.[112]

\subsection{Co-Localization Study in Intra and Extra Cellular Spaces}

A co-localization study of $\mathrm{TiO}_{2} \mathrm{NMs}$ with ions, lipid and protein related elements, as $\mathrm{P}$ and $\mathrm{S}$, the signaling related element $\mathrm{Ca}$, as well as with trace elements, $\mathrm{Fe}$ and $\mathrm{Cu}$, has been performed on $\mathrm{TiO}_{2}$ 
exposed cells intracellularly (Figure 8 B and S 7 B) and extracellularly in NM containing medium, DMEM (Figure $8 \mathrm{~A}$ and S $7 \mathrm{~A}$ ). A precise evaluation of the co-localization behavior was done by a quantitative analysis of element associations on the $\mathrm{TiO}_{2}$ surface within the cells and in extracellular space (Figure $8 \mathrm{C}$ ). Only cells with completely internalized $\mathrm{TiO}_{2} \mathrm{NMs}$ were taken into account for quantitative analysis of cellular element co-localization with titanium.

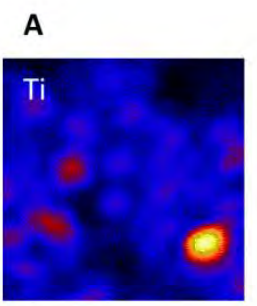

B

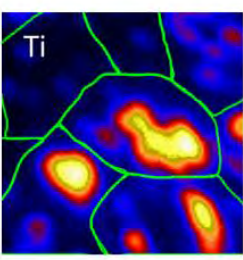

C

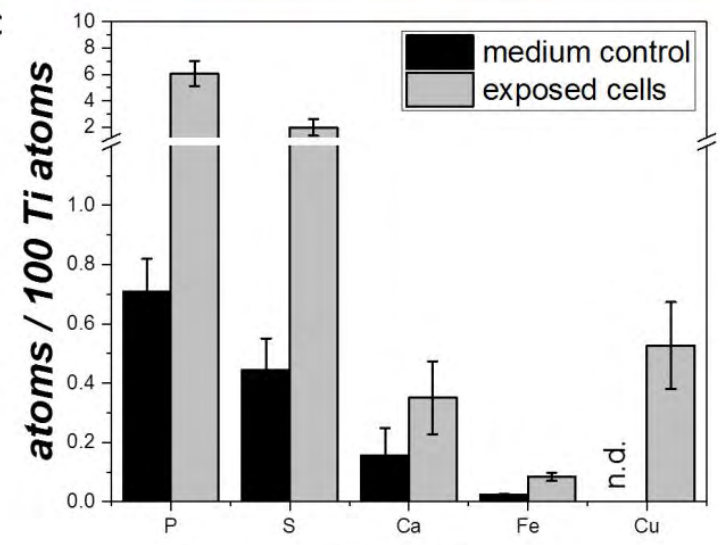

Element

\section{Control}

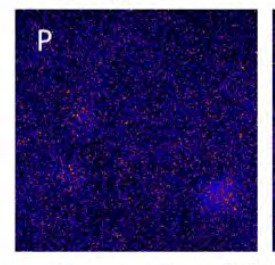

Caco-2 + NM103 $100 \mu \mathrm{g} \mathrm{ml}^{-1} 12 \mathrm{~h}$
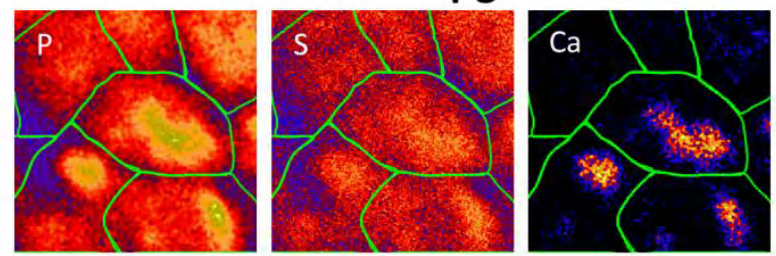

minimum

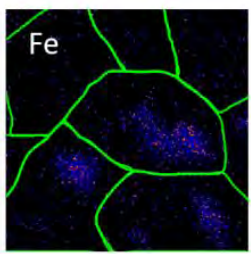

maximum
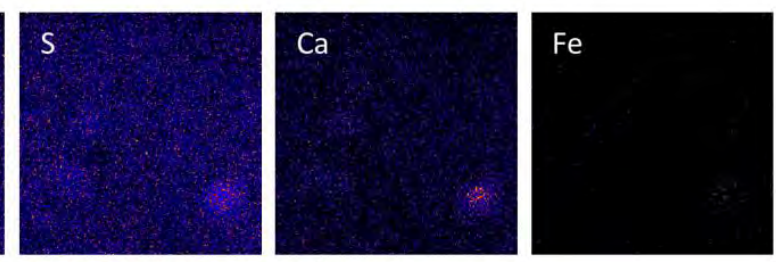

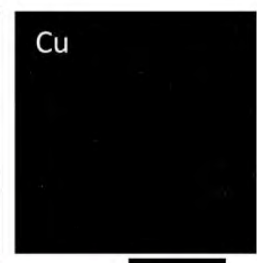

$10 \mu \mathrm{m}$

$15 \mu \mathrm{m}$

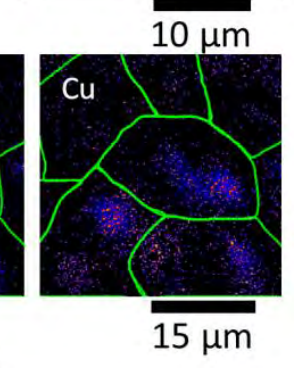

Figure 8. (A) $\mu \mathrm{PIXE}$ element maps of $\mathrm{TiO}_{2} \mathrm{NM} 103$ in DMEM medium before exposure to cells (control) and (B) Caco-2 cells exposed to $100 \mu \mathrm{g} \mathrm{ml}^{-1} \mathrm{TiO}_{2} \mathrm{NM103}$ over $12 \mathrm{~h}$. (C) Quantitative analysis of element colocalization with $\mathrm{TiO}_{2} \mathrm{NM} 103$ in extracellular (medium control) and intracellular spaces (exposed cells).

Associations between phosphorus, sulfur, calcium, iron and titanium have been visualized in the element maps of both $\mathrm{TiO}_{2} \mathrm{NMs}$ dispersed in DMEM medium (Figure $8 \mathrm{~A}$ and $\mathrm{S} 7 \mathrm{~A}$ ). The intracellular element distribution patterns of cells exposed to NM103 over $12 \mathrm{~h}$ reveals a clear colocalization of cellular elements such as $\mathrm{P}, \mathrm{S}, \mathrm{Ca}, \mathrm{Fe}$ and $\mathrm{Cu}$ with titanium (Figure $8 \mathrm{~B}$ ). A similar pattern of co-localization between NM104 and cell intrinsic elements was observed in the element maps (S 7 B).

Quantitative analysis of element co-localization was performed in extra and intracellular spaces only for hydrophobic NM103 due to its high cellular uptake rate. The RBS and PIXE spectra were

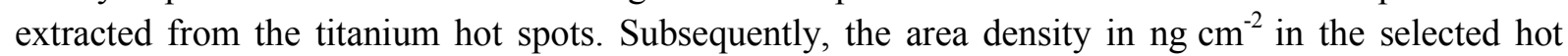
spots was determined. Afterwards, the area density was corrected by the cellular background derived from the hot spots excluded area.

The amount of P co-localized with Ti was increased by a factor of eight within the exposed cells compared to medium controls. The sulfur and calcium amount was five and two times larger, respectively. The iron association with the NM surface was four times stronger in the cells than in medium. Around 0.5 atoms of copper per $100 \mathrm{Ti}$ atoms were found to be co-localized within the cells. 
The copper content was thus five times higher compared to iron one on the surface of NMs. The NM associated copper content was below the detection limit in DMEM.

The results demonstrate a pronounced affinity of $\mathrm{P}, \mathrm{S}, \mathrm{Ca}$ and $\mathrm{Fe}$ to the surface of $\mathrm{TiO}_{2} \mathrm{NMs}$ both in DMEM cell medium and inside the Caco-2 cells. One may thus conclude that the surface of NMs dispersed in culture medium is most likely covered by proteins, phosphate and $\mathrm{Ca}$ ions. $\mathrm{Ca}$ ions tend to form at neutral $p H$ a barely soluble salt with phosphate ions known as hydroxyapatite. The apatite coating is known to interact strongly with cell membranes [113] and was used as a transfection agent employed for the transport of genetic material into cells.[114] Therefore, it can be expected that the modification of the surface with calcium and phosphate ions in cell medium might strongly affect the uptake and toxicological impact of the NMs.

Inside the cells a remarkable increase of $\mathrm{P}, \mathrm{S}, \mathrm{Ca}, \mathrm{Fe}$ and $\mathrm{Cu}$ content on the surface of $\mathrm{TiO}_{2}$ (Figure 8 B, C) could be associated with the post modification of the NM surface with lipids, lipoproteins, metal binding proteins, calcium and phosphate ions of the cytoplasm. NMs could bind S- and P-containing biomolecules, such as glutathione, phosphoadenosine phosphosulfate, S-rich transport proteins,[115] to their surface and affect the homeostasis of $\mathrm{Cu}, \mathrm{Fe}$ and $\mathrm{Zn}$ elements intracellularly (Figure 8). The immobilization of sulfur containing biomolecules could have severe consequences as they are known to exert important functions in living organisms and are involved in metal's transport, free radicals scavenging, protein synthesis and detoxification. [116, 117]

An increased amount of intrinsic sulfur and iron elements was found at the surface of $\mathrm{TiO}_{2}$ hot spots inside the Caco-2 cells (Figure $8 \mathrm{~B}, \mathrm{C}$ ). This could be an indication for enrichment of iron-sulfur cluster proteins on the $\mathrm{TiO}_{2}$ surface, which are involved in the mitochondrial respiratory chain.

The co-localization study has revealed that the internalized NMs were able not only to impair the cellular homeostasis (Figure 7), but also to induce intracellular redistributions of metabolical relevant elements as $\mathrm{P}, \mathrm{S}, \mathrm{Ca}, \mathrm{Fe}$ and $\mathrm{Cu}$ (Figure $8 \mathrm{~B}$ ).

\section{Conclusion}

Label-free quantitative imaging tools, $\mu \mathrm{PIXE}$ and $\mu \mathrm{RBS}$, allow simultaneous quantification and visualization of NMs and cellular intrinsic elements at single cell level. This is a prerequisite for correlating NM uptake with adverse effects on a quantitative basis given by strongly the inhomogeneous NM uptake patterns as it is often found in cell cultures. These advanced techniques in combination with classic toxicological methods have the potential for the development of risk assessment tools based on a deeper understanding of the mode of action of NM in biological environments.

Single cell analysis has revealed a strongly inhomogeneous $\mathrm{TiO}_{2}$ load across a cell population resembling a log-normal distribution suggesting endocytosis as the uptake mechanism. Outliner cells with a high NM-load can be easily identified by the applied single cell analysis approach. In case of hydrophilic $\mathrm{TiO}_{2}$ particles, high-load cells were not as frequently observed as it was the case for hydrophobic $\mathrm{TiO}_{2}$. Furthermore, the mean size of NM aggregates within the cells was up to 3 times smaller in case of hydrophilic particles compared to hydrophobic ones. High-load cells are rather important from a toxicological point of view, because such cells might be seen as initial points of adverse effects and can lead to long-term consequences on a level of the whole organism.

The cellular NM load was proven to be highly dependent on exposure conditions for the hydrophobic NMs, with uptake efficiency up to $14 \%$ of the administered NMs. In case of the hydrophilic NMs the uptake efficiency was around $3 \%$, independent from the exposure scenario.

The uptake of NM103 may be facilitated by hydrophobic interactions with the cell membrane in interplay with the $\beta$-actin enriched $\mathrm{NM}$ protein corona. Internalization of $\mathrm{TiO}_{2} \mathrm{NMs}$ of both kinds was studied by multiple methods, namely $\mu$ RBS, TEM and ToF-SIMS. 
The extracellular and intracellular modification of the NM surface was visualized and quantified at single cell level. For the first time it was shown and quantified that the presence of NMs in cells led to dysregulation of cellular homeostasis and to redistribution of the metabolically relevant elements, $\mathrm{P}, \mathrm{S}$, $\mathrm{Ca}, \mathrm{Fe}$ and $\mathrm{Cu}$, which became co-localized with NMs inside cells. A significant change in the cellular household of these elements may lead to unpredictable long term effects on the level of the whole organism.

\section{Experimental Section}

Two $\mathrm{TiO}_{2}$ NMs (hydrophobic NM103 and hydrophilic NM104) were delivered from Joint Research Centre (JRC), Ispra, Italy. BSA and Superfibronectin from human plasma were purchased from Sigma-Aldrich. FBS was bought from Capricorn Scientific GmbH (Ebsdorfergrund, Germany). Trypsin-EDTA was ordered from Biowest (Nuaille, France). DMEM / High Glucose $500 \mathrm{ml}$ (+4.00 mM L-Glutamine, $+4500 \mathrm{mg} \mathrm{L}^{-1}$ Glucose, +Sodium Pyruvate) was bought from GeHealthcare (Berlin, Germany). PP-foil was purchased from Goodfellow GmbH (Bad Nauheim, Germany). Human colon adenocarcinoma Caco-2 cell line (DSMZ no.: ACC 169) was ordered from Leibniz Institute DSMZ-German Collection of Microorganisms and Cell Cultures (Braunschweig, Germany).

\subsection{Chemicals}

Two $\mathrm{TiO}_{2}$ NMs (hydrophobic NM103 and hydrophilic NM104) were delivered from Joint Research Centre (JRC), Ispra, Italy. BSA and Superfibronectin from human plasma were purchased from Sigma-Aldrich. FBS was bought from Capricorn Scientific GmbH (Ebsdorfergrund, Germany). Trypsin-EDTA was ordered from Biowest (Nuaille, France). DMEM / High Glucose $500 \mathrm{ml}$ (+4.00 mM L-Glutamine, $+4500 \mathrm{mg} \mathrm{L}^{-1}$ Glucose, +Sodium Pyruvate) was bought from GeHealthcare (Berlin, Germany). PP-foil was purchased from Goodfellow GmbH (Bad Nauheim, Germany). Human colon adenocarcinoma Caco-2 cell line (DSMZ no.: ACC 169) was ordered from Leibniz Institute DSMZ-German Collection of Microorganisms and Cell Cultures (Braunschweig, Germany).

\subsection{Cell Culture}

Caco- 2 cells were cultivated in cell culture flasks under controlled conditions at $37{ }^{\circ} \mathrm{C}$ in a humidified atmosphere containing $5 \% \mathrm{CO}_{2}$. As cell culture medium, DMEM supplemented with $10 \%$ FBS and $1 \%$ Penicillin/Streptomycin (25000 units Penicillin, $25 \mathrm{mg}$ Streptomycin) was used.

For IBM experiments PP-foil was sterilized by using $\mathrm{H}_{2} \mathrm{O}_{2}$ and UV light. The foil was mounted between two plastic rings to form a well with an area of around $8.3 \mathrm{~cm}^{2}$. Afterwards the foil was coated with $5 \mu \mathrm{g} \mathrm{ml}^{-1}$ superfibronectin. The cells were seeded at a density of around $15000 \mathrm{cells} \mathrm{cm}^{-2}$. After the Caco-2 cells reached confluence they were cultivated for 21 more days to obtain differentiated cells. The medium was refreshed every 2 to 3 days.

After exposure to $\mathrm{TiO}_{2} \mathrm{NMs}$ the cells were washed three times with phosphate-buffered saline PBS and fixed for 15 minutes with iced methanol at $4{ }^{\circ} \mathrm{C}$. Afterwards the cells were washed two more times with methanol. Dried cells were stored at $4{ }^{\circ} \mathrm{C}$.

For TEM experiments, Caco2 cells were cultivated in dishes in the same conditions as previously described. Cells were rinsed twice with PBS and with $0.15 \mathrm{M} \mathrm{Na}$ cacodylate buffer ( $p H$ 7.2) before TEM conventional sample preparation.

A dedicated cryogenic sample preparation technique with a high cooling rate was used in case of ToFSIMS experiments.[43, 118] Liquid propane was cooled down by using liquid nitrogen, thus preventing evaporation of propane at the contact surface of the immersed specimen. This allowed accelerated cooling rates of up to $104 \mathrm{~K} \mathrm{~s}^{-1}$ on the surface of the sample to preserve the physiological state of the cells. 


\subsection{Nanomaterial Dispersion and Characterization}

NM stock solutions in Millipore water containing BSA were prepared by ultra-sonic homogenization following the NANOGENOTOX dispersion protocol.[71] The presence of $0.05 \%$ BSA stabilized the NMs by building an albumin corona on the NMs surface during ultra-sonication. Afterwards the NMs were dispersed in cell culture medium (DMEM containing FBS).

DLS and NTA were used to characterize the albumin modified NMs in stock solution containing $0.05 \%$ BSA in water, as well as under cell culture conditions in DMEM with $10 \%$ FBS. The stability of the NMs was assessed at $0 \mathrm{~h}, 24 \mathrm{~h}$ and $48 \mathrm{~h}$, after the preparation. The samples were re-suspended by vortexing before the measurements. All measured sizes were averaged from at least three independent experiments.

\subsubsection{Dynamic Light Scattering}

DLS was performed with a Brookhaven Omni zetaPALS. The machine used a $659 \mathrm{~nm}$ laser and a $90^{\circ}$ set up to detect the scattered light. The measurements were performed at a particle concentration of $100 \mu \mathrm{g} \mathrm{ml}^{-1}$. Experiments were performed at $25^{\circ} \mathrm{C}$. The intensity weighted size distribution was calculated by means of the cumulant algorithm. $[72,73]$

\subsubsection{Nanoparticle Tracking Analysis}

NTA data were recorded using a NanoSight LM10 (Malvern Instruments Ltd, Worcestershire, UK), equipped with a $532 \mathrm{~nm}$ laser. To achieve good experimental conditions, the particle concentration was set to $10^{8}-10^{9}$ particles $\mathrm{ml}^{-1}$ by diluting the samples in Millipore water. The temperature was set to $25^{\circ} \mathrm{C}$. Each sample was measured at five different positions in three independent experiments.

\subsubsection{Corona Protein Investigation}

Adsorption of proteins on $\mathrm{TiO}_{2} \mathrm{NMs}$, prepared correspondingly to the NANOGENOTOX dispersion protocol, were analyzed after $24 \mathrm{~h}$ incubation $\left(37^{\circ} \mathrm{C}, 5 \% \mathrm{CO}_{2}\right)$ of $100 \mu \mathrm{g} \mathrm{Ti} \mathrm{ml}{ }^{-1}$ samples in serumcontaining cell culture medium. Afterwards, NMs were isolated via centrifugation in a Beckman Optima L centrifuge (Beckman, Unterschleissheim, Germany) for $1 \mathrm{~h}$ at $48.3 \mathrm{x}$ g. Supernatants were removed. Pellets were washed by resuspending in $10 \mathrm{ml} 50 \mathrm{mM}$ sodium bicarbonate and transferring into a fresh tube. This washing step was repeated 3 times. In the last step, the pellet was resuspended in $1 \mathrm{ml}$ and centrifuged for $1 \mathrm{~h}$ at $153.7 \mathrm{xg}$. With these pellets, 2D-sodium dodecyl sulfatepolyacrylamide gel electrophoresis (SDS-PAGE) was performed. Isoelectric focusing was done with $7 \mathrm{M}$ urea and a $2 \mathrm{M}$ thiourea-containing lysis buffer, in this buffer the proteins detach by denaturation from the NMs. After a second dimension migration (SDS-PAGE), gels were stained with ruthenium and photographed using a VersaDoc imager (VersaDoc MP 4000, BioRad, USA, excitation $450 \mathrm{~nm}$, emission $605 \mathrm{~nm}$ ). Semi-quantitative data evaluation was carried out by manually comparing 4 replicates per sample using a VersaDoc imager. Spots were picked by self-made SpotXpress Spotpicker and digested by tryptic digestion over night for MALDI-TOF (matrix-assisted laser desorption ionization-mass spectrometry) protein identification (Bruker Ultraflex II, Bruker, Berlin, Germany). The composition of proteins in cell culture medium was used as reference to the protein composition in NM corona.

\subsection{Label-Free Dosimetric and Imaging Methods}

\subsubsection{Ion Beam Microscopy}

IBM measurements were performed at LIPSION nanoprobe at Leipzig University. A $2.3 \mathrm{MeV}$ proton beam was supplied by a $3 \mathrm{MV}$ Singletron ${ }^{\mathrm{TM}}$ particle accelerator. To avoid interaction between the accelerated protons and atmospheric gas, a vacuum of $5 \times 10^{-5}$ to $10^{-7}$ Torr was applied. Energy 
separation of the protons in the beam was done by applying a magnetic field orthogonal to the beam direction. Lorentz and centripetal forces allow only protons with energy of $2.3 \mathrm{MeV}$ to pass the energy filter. A low energy spread of about $1 \mathrm{keV}$ was obtained for protons.

To obtain a spatial resolution of ca $1 \mu \mathrm{m}$ objective and aperture slits $(200$ and $300 \mu \mathrm{m})$ were used in combination with a focusing unit, consisting of four quadrupole lenses arranged in two duplets forming a Russian quadruplet.[119, 120] A raster unit enables to deflect the beam in two orthogonal directions and to scan areas between $12.5 \times 12.5 \mu \mathrm{m}^{2}$ and around $2 \times 2 \mathrm{~mm}^{2}$. While the beam scans the sample, characteristic X-rays and backscattered protons are detected simultaneously. $\mu$ PIXE spectra were obtained at detection angle of $135^{\circ}$ using a high-purity Germanium detector with an active area of $95 \mathrm{~mm}^{2}$ by Canberra (Rüsselsheim, Germany). The PIXE detector was calibrated using element standards of Astimex Standards Ldt - Serial EPX1 SPEC 25-53+FC (Toronto, Canada). The detailed procedure is described elsewhere.[121] $\mu$ RBS was recorded by a Canberra PIPS detector with backscattering angle of $173^{\circ}$. For data analysis GeoPIXE 5.1b and SIMNRA 6.06.software were used.

\subsubsection{Transmission Electron Microscopy}

The cells were fixed by drop wise addition of glutaraldehyde $(2.5 \%)$ for $45 \mathrm{~min}$. They were rinsed several times with $0.15 \mathrm{M} \mathrm{Na}$ cacodylate buffer and post fixed with $1 \%$ osmium tetroxide for $45 \mathrm{~min}$. After further rinsing with cacodylate buffer, the samples were dehydrated through an ethanol gradient from $70 \%$ to $100 \%$ and infiltrated in a mixture of acetone-epon resin $(50 / 50)$ for $3 \mathrm{~h}$, then, in pure epon resin for $16 \mathrm{~h}$. Finally, the samples were embedded in DMP30-epon for $24 \mathrm{~h}$ at $60{ }^{\circ} \mathrm{C}$. Ultra-thin sections $(90 \mathrm{~nm})$ were cut on a Leica UC7 ultra-cut in two different orientations, collected onto copper grids and double-stained with 4\% uranyl acetate then with lead citrate (Reynold solution). Examination was performed with JEOL 1400 electron microscope operated at $120 \mathrm{kV}$ equipped with a $2 \mathrm{k}$ x $2 \mathrm{k}$ camera from Gatan (Orius 1000).

\subsubsection{Time of Flight Secondary Ion Mass Spectrometry}

All depth profiles were performed in dual beam mode on a ToF-SIMS V instrument (ION-TOF $\mathrm{GmbH}$, Münster, Germany) of the reflectron-type, equipped with a $30 \mathrm{keV}$ bismuth liquid metal ion gun as primary ion source, a $20 \mathrm{keV}$ argon gas cluster ion source both mounted at $45^{\circ}$ with respect to the sample surface and an electron flood gun. Primary and sputter ion currents were directly determined at $200 \mu$ s cycle time (i.e. a repetition rate of $5.0 \mathrm{kHz}$ ) using a Faraday cup located on a grounded sample holder. A pulse of $0.7 \mathrm{~ns}$ from the bunching system resulted in a mass resolution at $\mathrm{m} / \mathrm{z}<500$ in positive ion mode. The primary ion dose was controlled below 1012 ions $\mathrm{cm}^{-2}$ to ensure static SIMS conditions. The primary ion gun scanned a field of view of $200 \times 200 \mu \mathrm{m}^{2}$ applying a $512 \times 512$ pixel measurement raster. Once the primary ion gun was aligned, a ToF-SIMS mass spectrum was generated by summing the detected secondary ion intensities and plotting them against the mass channels. The analytical methodology was described in detail elsewhere.[43, 122-124] The data were evaluated using the Surface Lab software (ION-TOF GmbH, Münster, Germany).

\subsection{Statistical Methods}

For IBM measurements two technical replications and at least 32 single cells were investigated for each exposure conditions. The nonparametric Mann-Whitney U test was used to determine statistical significances between two groups. The test was chosen because it does not require the assumption of normal distributions.[125-127] The conservative Bonferroni correction was applied in case of multiple hypotheses to avoid false significances.[128] Significance values are determined as follows: $* \mathrm{P}<0.05 ; * * \mathrm{P}<0.01 ; * * * \mathrm{P}<0.001$.

\section{Acknowledgements}


This work is based on the research results of the bilateral French-German project SolNanoTOX, funded by the German Research Foundation (DFG, Project ID: DFG (FKZ ES-181/2-1, LA 3411/1-1 and LA 1177/9-1)) and the French National Research Agency (ANR, Project ID: ANR-13-IS10-0005). The authors would like to thank Carsten Pahnke and Joachim Starke from the Felix Bloch Institute for Solid State Physics, Leipzig University, for technical support at the LIPSION nanoprobe.

1. Baer, D.R., et al., Surface characterization of nanomaterials and nanoparticles: Important needs and challenging opportunities. J Vac Sci Technol A, 2013. 31(5): p. 50820.

2. Kelly, K.L., et al., The optical properties of metal nanoparticles: The influence of size, shape, and dielectric environment. Journal of Physical Chemistry B, 2003. 107(3): p. 668-677.

3. Martirosyan, A. and Y.J. Schneider, Engineered nanomaterials in food: implications for food safety and consumer health. Int J Environ Res Public Health, 2014. 11(6): p. 5720-50.

4. Bradley, E.L., L. Castle, and Q. Chaudhry, Applications of nanomaterials in food packaging with a consideration of opportunities for developing countries. Trends in Food Science \& Technology, 2011. 22(11): p. 604-610.

5. Chaudhry, Q., et al., Applications and implications of nanotechnologies for the food sector. Food Additives and Contaminants Part a-Chemistry Analysis Control Exposure \& Risk Assessment, 2008. 25(3): p. 241-258.

6. Gao, Y., et al., Metallic nanoparticle production and consumption in China between 2000 and 2010 and associative aquatic environmental risk assessment. Journal of Nanoparticle Research, 2013. 15(6).

7. Piccinno, F., et al., Industrial production quantities and uses of ten engineered nanomaterials in Europe and the world. Journal of Nanoparticle Research, 2012. 14(9).

8. COMMISSION REGULATION (EU) No 1129/2011 of 11 November 2011 amending Annex II to Regulation (EC) No 1333/2008 of the European Parliament and of the Council by establishing a Union list of food additives. 2011.

9. Weir, A., et al., Titanium Dioxide Nanoparticles in Food and Personal Care Products. Environmental Science \& Technology, 2012. 46(4): p. 2242-2250.

10. Chen, J.Y., et al., In vivo acute toxicity of titanium dioxide nanoparticles to mice after intraperitioneal injection. Journal of Applied Toxicology, 2009. 29(4): p. 330-337.

11. Fisichella, M., et al., Intestinal toxicity evaluation of TiO2 degraded surface-treated nanoparticles: a combined physico-chemical and toxicogenomics approach in caco-2 cells. Particle and Fibre Toxicology, 2012. 9.

12. Simon-Deckers, A., et al., In vitro investigation of oxide nanoparticle and carbon nanotube toxicity and intracellular accumulation in A549 human pneumocytes. Toxicology, 2008. 253(1-3): p. 137-146.

13. Yazdi, A.S., et al., Nanoparticles activate the NLR pyrin domain containing 3 (Nlrp3) inflammasome and cause pulmonary inflammation through release of IL-1 alpha and IL-1 beta. Proceedings of the National Academy of Sciences of the United States of America, 2010. 107(45): p. 19449-19454.

14. Heringa, M.B., et al., Risk assessment of titanium dioxide nanoparticles via oral exposure, including toxicokinetic considerations. Nanotoxicology, 2016. 10(10): p. 1515-1525.

15. Carbon Black, Titanium Dioxide, and Talc,. 2010, IARC (International Agency For Research Of Cancer).

16. Anjilvel, S. and B. Asgharian, A Multiple-Path Model of Particle Deposition in the Rat Lung. Fundamental and Applied Toxicology, 1995. 28(1): p. 41-50.

17. Iavicoli, I., V. Leso, and A. Bergamaschi, Toxicological Effects of Titanium Dioxide Nanoparticles: A Review of In Vivo Studies. Journal of Nanomaterials, 2012.

18. Grande, F. and P. Tucci, Titanium Dioxide Nanoparticles: a Risk for Human Health? Mini Rev Med Chem, 2016. 16(9): p. 762-9.

19. Wu, J., et al., Toxicity and penetration of TiO2 nanoparticles in hairless mice and porcine skin after subchronic dermal exposure. Toxicol Lett, 2009. 191(1): p. 1-8. 
20. Geraets, L., et al., Tissue distribution and elimination after oral and intravenous administration of different titanium dioxide nanoparticles in rats. Particle and Fibre Toxicology, 2014. 11.

21. Wang, J.X., et al., Acute toxicity and biodistribution of different sized titanium dioxide particles in mice after oral administration. Toxicology Letters, 2007. 168(2): p. 176-185.

22. Tassinari, R., et al., Oral, short-term exposure to titanium dioxide nanoparticles in SpragueDawley rat: focus on reproductive and endocrine systems and spleen. Nanotoxicology, 2014. 8(6): p. 654-662.

23. Jani, P.U., D.E. Mccarthy, and A.T. Florence, Titanium-Dioxide (Rutile) Particle Uptake from the Rat Gi Tract and Translocation to Systemic Organs after Oral-Administration. International Journal of Pharmaceutics, 1994. 105(2): p. 157-168.

24. Zhao, X.Y., et al., Nanosized TiO2-Induced Reproductive System Dysfunction and Its Mechanism in Female Mice. Plos One, 2013. 8(4).

25. Kreyling, W.G., et al., Quantitative biokinetics of titanium dioxide nanoparticles after oral application in rats: Part 2. Nanotoxicology, 2017. 11(4): p. 443-453.

26. Pele, L.C., et al., Pharmaceuticalffood grade titanium dioxide particles are absorbed into the bloodstream of human volunteers. Particle and Fibre Toxicology, 2015. 12.

27. Sun, H., et al., The Caco-2 cell monolayer: usefulness and limitations. Expert Opin Drug Metab Toxicol, 2008. 4(4): p. 395-411.

28. Alvarez-Hernandez, X., G.M. Nichols, and J. Glass, Caco-2 cell line: a system for studying intestinal iron transport across epithelial cell monolayers. Biochim Biophys Acta, 1991. 1070(1): p. 205-8.

29. Kang, T., et al., In vitro toxicity of different-sized $\mathrm{ZnO}$ nanoparticles in Caco-2 cells. Nanoscale Res Lett, 2013. 8(1): p. 496.

30. Brun, E., et al., Titanium dioxide nanoparticle impact and translocation through ex vivo, in vivo and in vitro gut epithelia. Particle and Fibre Toxicology, 2014. 11.

31. Koeneman, B.A., et al., Toxicity and cellular responses of intestinal cells exposed to titanium dioxide. Cell Biol Toxicol, 2010. 26(3): p. 225-38.

32. Loeschner, K., et al., Detection and characterisation of aluminium-containing nanoparticles in Chinese noodles by single particle ICP-MS. Food Addit Contam Part A Chem Anal Control Expo Risk Assess, 2018. 35(1): p. 86-93.

33. Gitrowski, C., A.R. Al-Jubory, and R.D. Handy, Uptake of different crystal structures of TiO2 nanoparticles by Caco-2 intestinal cells. Toxicology Letters, 2014. 226(3): p. 264-276.

34. Poon, C.K., et al., Fluorescent Labeling and Biodistribution of Latex Nanoparticles Formed by Surfactant-Free RAFT Emulsion Polymerization. Macromolecular Bioscience, 2017. 17(10).

35. Bose, K., et al., A Correlative Analysis of Gold Nanoparticles Internalized by A549 Cells. Particle \& Particle Systems Characterization, 2014. 31(4): p. 439-448.

36. Tarantini, A., et al., Toxicity, genotoxicity and proinflammatory effects of amorphous nanosilica in the human intestinal Caco-2 cell line. Toxicol In Vitro, 2015. 29(2): p. 398-407.

37. Reifarth, M., S. Hoeppener, and U.S. Schubert, Uptake and Intracellular Fate of Engineered Nanoparticles in Mammalian Cells: Capabilities and Limitations of Transmission Electron MicroscopyPolymer-Based Nanoparticles. Advanced Materials, 2018. 30(9).

38. Salehi, H., et al., Confocal Raman spectroscopy to monitor intracellular penetration of TiO2 nanoparticles. Journal of Raman Spectroscopy, 2014. 45(9): p. 807-813.

39. Romero, G., et al., Surface Engineered Poly(lactide-co-glycolide) Nanoparticles for Intracellular Delivery: Uptake and Cytotoxicity - A Confocal Raman Microscopic Study. Biomacromolecules, 2010. 11(11): p. 2993-2999.

40. Romero, G., et al., Stepwise surface tailoring of carbon nanotubes with polyelectrolyte brushes and lipid layers to control their intracellular distribution and "in vitro" toxicity. Soft Matter, 2011. 7(15): p. 6883-6890.

41. Estrela-Lopis, I., et al., Nanoparticle uptake and their co-localization with cell compartments a confocal Raman microscopy study at single cell level. J. Physics:CS, 2011. 304: p. 1-10.

42. Qiu, Y., et al., Cell uptake, intracellular distribution, fate and reactive oxygen species generation of polymer brush engineered CeO2-x NPs. Nanoscale, 2015. 7(15): p. 6588-6598. 
43. Haase, A., et al., Application of laser postionization secondary neutral mass spectrometry/time-of-flight secondary ion mass spectrometry in nanotoxicology: visualization of nanosilver in human macrophages and cellular responses. ACS Nano, 2011. 5(4): p. 305968.

44. Hagenhoff, B., et al., Detection of micro- and nano-particles in animal cells by ToF-SIMS 3D analysis. Surface and Interface Analysis, 2013. 45(1): p. 315-319.

45. Zhou, X.Y., et al., A quantitative study of the intracellular concentration of graphene/noble metal nanoparticle composites and their cytotoxicity. Nanoscale, 2014. 6(15): p. 8535-8542.

46. Lichtenstein, D., et al., Dosimetric quantification of coating-related uptake of silver nanoparticles. Langmuir, 2017.

47. Yang, Y.S.S., et al., High-throughput quantitation of inorganic nanoparticle biodistribution at the single-cell level using mass cytometry. Nature Communications, 2017. 8.

48. Zhang, Z.Y., et al., Tailoring Cellular Uptake of Gold Nanoparticles Via the Hydrophilic-toHydrophobic Ratio of their (Co)polymer Coating. Advanced Functional Materials, 2015. 25(22): p. 3433-3439.

49. Allouni, Z.E., et al., The effect of blood protein adsorption on cellular uptake of anatase TiO2 nanoparticles. Int J Nanomedicine, 2015. 10: p. 687-95.

50. Johansson, S.A.E., Particle-Induced X-Ray Emission Spectrometry (PIXE). 1995, New York: John Wiley \& Sons.

51. Carmona, A., G. Deves, and R. Ortega, Quantitative micro-analysis of metal ions in subcellular compartments of cultured dopaminergic cells by combination of three ion beam techniques. Anal Bioanal Chem, 2008. 390(6): p. 1585-94.

52. Fiedler, A., et al., Intracellular iron concentration of neurons with and without perineuronal nets. Nuclear Instruments \& Methods in Physics Research Section B-Beam Interactions with Materials and Atoms, 2007. 260(1): p. 153-158.

53. Govil, I.M., Proton Induced X-ray Emission - A tool for non-destructive trace element analysis. Current Science, 2001. 80(12): p. 1542-1549.

54. Lichtenstein, D., et al., It takes more than a coating to get nanoparticles through the intestinal barrier in vitro. European Journal of Pharmaceutics and Biopharmaceutics, 2016.

55. Veith, L., et al., Detection of $\mathrm{ZrO}(2)$ Nanoparticles in Lung Tissue Sections by Time-of-Flight Secondary Ion Mass Spectrometry and Ion Beam Microscopy. Nanomaterials (Basel), 2018. 8(1).

56. Llop, J., et al., Uptake, Biological Fate, and Toxicity of Metal Oxide Nanoparticles. Particle \& Particle Systems Characterization, 2014. 31(1): p. 24-35.

57. James, S.A., et al., Quantification of ZnO Nanoparticle Uptake, Distribution, and Dissolution within Individual Human Macrophages. Acs Nano, 2013. 7(12): p. 10621-10635.

58. Jacobsen, C. and J. Kirz, X-ray microscopy with synchrotron radiation. Nat Struct Biol, 1998. 5 Suppl: p. 650-3.

59. Jin, Q.L., et al., Preserving elemental content in adherent mammalian cells for analysis by synchrotron-based x-ray fluorescence microscopy. Journal of Microscopy, 2017. 265(1): p. 81-93.

60. Ugarte, M., G.W. Grime, and N.N. Osborne, Distribution of trace elements in the mammalian retina and cornea by use of particle-induced X-ray emission (PIXE): localisation of zinc does not correlate with that of metallothioneins. Metallomics, 2014. 6(2): p. 274-278.

61. Spemann, D., et al., Trace element content and magnetic properties of commercial HOPG samples studied by ion beam microscopy and SQUID magnetometry. Aip Advances, 2014. 4(10).

62. Drasler, B., et al., Quantifying nanoparticle cellular uptake: which method is best? Nanomedicine, 2017. 12(10): p. 1095-1099.

63. Elsaesser, A., et al., Quantification of nanoparticle uptake by cells using microscopical and analytical techniques. Nanomedicine, 2010. 5(9): p. 1447-1457.

64. Vanhecke, D., et al., Quantification of nanoparticles at the single-cell level: an overview about state-of-the-art techniques and their limitations. Nanomedicine, 2014. 9(12): p. 18851900 . 
65. Rashkow, J.T., et al., Quantification of single-cell nanoparticle concentrations and the distribution of these concentrations in cell population. Journal of the Royal Society Interface, 2014. 11(94).

66. Collins, A.R., et al., High throughput toxicity screening and intracellular detection of nanomaterials. Wiley Interdisciplinary Reviews: Nanomedicine and Nanobiotechnology, 2017. 9(1).

67. Laux, P., et al., Biokinetics of nanomaterials: The role of biopersistence. NanoImpact, 2017.

68. DeLoid, G.M., et al., Preparation, characterization, and in vitro dosimetry of dispersed, engineered nanomaterials. Nature Protocols, 2017. 12(2): p. 355-371.

69. Rassmussen, K.M., Titanium Dioxide, NM-100, NM-101, NM-102, NM-103, NM-104, NM105: Characterisation and Physico-Chemical Properties, in Joint Research Centre (JRC) science and policy reports. 2014.

70. Krause, B., et al., Characterization of aluminum, aluminum oxide and titanium dioxide nanomaterials using a combination of methods for particle surface and size analysis. RSC Advances, 2018. 8(26): p. 14377-14388.

71. Jensen K. A., K.Y., Christiansen E., Jacobsen N. R., Wallin H., Guiot C., Spalla O., Witschger O. Web-Report. The generic NANOGENOTOX dispersion protocol - Standard Operation Procedure (SOP). 2011.

72. Goldburg, W.I., Dynamic light scattering. American Journal of Physics, 1999. 67(12): p. 1152-1160.

73. Koppel, D.E., Analysis of Macromolecular Polydispersity in Intensity Correlation Spectroscopy - Method of Cumulants. Journal of Chemical Physics, 1972. 57(11): p. 4814-\&.

74. Frisken, B.J., Revisiting the method of cumulants for the analysis of dynamic light-scattering data. Applied Optics, 2001. 40(24): p. 4087-4091.

75. Filipe, V., A. Hawe, and W. Jiskoot, Critical Evaluation of Nanoparticle Tracking Analysis (NTA) by NanoSight for the Measurement of Nanoparticles and Protein Aggregates. Pharmaceutical Research, 2010. 27(5): p. 796-810.

76. Lundqvist, M., et al., Nanoparticle size and surface properties determine the protein corona with possible implications for biological impacts. Proceedings of the National Academy of Sciences of the United States of America, 2008. 105(38): p. 14265-14270.

77. Bertoli, F., et al., The Intracellular Destiny of the Protein Corona: A Study on its Cellular Internalization and Evolution. Acs Nano, 2016. 10(11): p. 10471-10479.

78. Conner, S.D. and S.L. Schmid, Regulated portals of entry into the cell. Nature, 2003. 422(6927): p. 37-44.

79. Gorji, H.T. and J. Haddadnia, A Novel Method for Early Diagnosis of Alzheimer's Disease Based on Pseudo Zernike Moment from Structural Mri. Neuroscience, 2015. 305: p. 361-371.

80. Scherbart, A.M., et al., Contrasting macrophage activation by fine and ultrafine titanium dioxide particles is associated with different uptake mechanisms. Particle and Fibre Toxicology, 2011. 8.

81. Huerta-Garcia, E., et al., Internalization of titanium dioxide nanoparticles by glial cells is given at short times and is mainly mediated by actin reorganization-dependent endocytosis. Neurotoxicology, 2015. 51: p. 27-37.

82. Allouni, Z.E., et al., Role of physicochemical characteristics in the uptake of TiO2 nanoparticles by fibroblasts. Toxicology in Vitro, 2012. 26(3): p. 469-479.

83. Yang, S.O., et al., Biomimetic, synthetic HDL nanostructures for lymphoma. Proceedings of the National Academy of Sciences of the United States of America, 2013. 110(7): p. 25112516.

84. Yu, X., et al., Changes of serum parameters of TiO(2) nanoparticle-induced atherosclerosis in mice. J Hazard Mater, 2014. 280: p. 364-71.

85. Jalili, P., et al., Investigation of the in vitro genotoxicity of two rutile TiO2 nanomaterials in human intestinal and hepatic cells and evaluation of their interference with toxicity assays. NanoImpact, 2018. 11: p. 69-81.

86. Septiadi, D., et al., Nanoparticle-Cell Interaction: A Cell Mechanics Perspective. Advanced Materials, 2018. 30(19). 
87. Veronesi, G., et al., Structural properties of rutile TiO2 nanoparticles accumulated in a model of gastrointestinal epithelium elucidated by micro-beam $x$-ray absorption fine structure spectroscopy. Applied Physics Letters, 2012. 100(21).

88. Mahler, G.J., et al., Oral exposure to polystyrene nanoparticles affects iron absorption. Nature Nanotechnology, 2012. 7(4): p. 264-U1500.

89. Hansen, G.H., et al., Endocytic trafficking from the small intestinal brush border probed with FM dye. American Journal of Physiology-Gastrointestinal and Liver Physiology, 2009. 297(4): p. G708-G715.

90. Koeneman, B.A., et al., Toxicity and cellular responses of intestinal cells exposed to titanium dioxide. Cell Biology and Toxicology, 2010. 26(3): p. 225-238.

91. Furusawa, C., et al., Ubiquity of log-normal distributions in intra-cellular reaction dynamics. Biophysics (Nagoya-shi), 2005. 1: p. 25-31.

92. Limpert, E., W.A. Stahel, and M. Abbt, Log-normal distributions across the sciences: Keys and clues. Bioscience, 2001. 51(5): p. 341-352.

93. Maheshri, N. and E.K. O'Shea, Living with noisy genes: How cells function reliably with inherent variability in gene expression. Annual Review of Biophysics and Biomolecular Structure, 2007. 36: p. 413-434.

94. Baum, P., et al., The role of nerve inflammation and exogenous iron load in experimental peripheral diabetic neuropathy (PDN). Metabolism-Clinical and Experimental, 2016. 65(4): p. 391-405.

95. Bourassa, M.W. and L.M. Miller, Metal imaging in neurodegenerative diseases. Metallomics, 2012. 4(8): p. 721-738.

96. Krzysciak, W., et al., Iron content (PIXE) in competent and incompetent veins is related to the vein wall morphology and tissue antioxidant enzymes. Bioelectrochemistry, 2012. 87: p. 114123.

97. Ren, M., et al., Nuclear microscopy of rat colon epithelial cells. Nuclear Instruments \& Methods in Physics Research Section B-Beam Interactions with Materials and Atoms, 2011. 269(20): p. 2264-2268.

98. Pierre, F., et al., Beef meat and blood sausage promote the formation of azoxymethaneinduced mucin-depleted foci and aberrant crypt foci in rat colons. Journal of Nutrition, 2004. 134(10): p. 2711-2716.

99. Norat, T., et al., Meat, fish, and colorectal cancer risk: The European prospective investigation into cancer and nutrition. Journal of the National Cancer Institute, 2005. 97(12): p. 906-916.

100. Sullivan, J.L., The Iron Paradigm of Ischemic Heart-Disease. American Heart Journal, 1989. 117(5): p. 1177-1188.

101. Ponka, P., C. Beaumont, and D.R. Richardson, Function and regulation of transferrin and ferritin. Seminars in Hematology, 1998. 35(1): p. 35-54.

102. Tappel, A., Heme of consumed red meat can act as a catalyst of oxidative damage and could initiate colon, breast and prostate cancers, heart disease and other diseases. Medical Hypotheses, 2007. 68(3): p. 562-564.

103. Qamar, K., et al., Malabsorption of iron as a cause of iron deficiency anemia in postmenopausal women. Pakistan Journal of Medical Sciences, 2015. 31(2): p. 304-308.

104. Squitti, R., et al., Excess of serum copper not related to ceruloplasmin in Alzheimer disease. Neurology, 2005. 64(6): p. 1040-6.

105. Halliwell, B. and J.M.C. Gutteridge, Oxygen-Toxicity, Oxygen Radicals, Transition-Metals and Disease. Biochemical Journal, 1984. 219(1): p. 1-14.

106. Foster, M. and S. Samman, Zinc and Regulation of Inflammatory Cytokines: Implications for Cardiometabolic Disease. Nutrients, 2012. 4(7): p. 676-694.

107. Finamore, A., et al., Zinc deficiency induces membrane barrier damage and increases neutrophil transmigration in Caco-2 cells. Journal of Nutrition, 2008. 138(9): p. 1664-1670.

108. Jansen, J., W. Karges, and L. Rink, Zinc and diabetes--clinical links and molecular mechanisms. J Nutr Biochem, 2009. 20(6): p. 399-417.

109. Sturniolo, G.C., et al., Zinc supplementation tightens "leaky gut" in Crohn's disease. Inflammatory Bowel Diseases, 2001. 7(2): p. 94-98. 
110. Sempertegui, F., et al., Low concentrations of zinc in gastric mucosa are associated with increased severity of Helicobacter pylori-induced inflammation. Helicobacter, 2007. 12(1): p. 43-48.

111. Guo, Z., et al., Titanium dioxide nanoparticle ingestion alters nutrient absorption in an in vitro model of the small intestine. NanoImpact, 2017. 5: p. 70-82.

112. Bettini, S., et al., Food-grade TiO2 impairs intestinal and systemic immune homeostasis, initiates preneoplastic lesions and promotes aberrant crypt development in the rat colon. Scientific Reports, 2017. 7.

113. Melcrova, A., et al., The complex nature of calcium cation interactions with phospholipid bilayers, in Scientific Reports. 2016.

114. Graham, F.L. and A.J. van der Eb, A new technique for the assay of infectivity of human adenovirus 5 DNA. Virology, 1973. 52(2): p. 456-67.

115. Palego L., B.L., Giannaccini G, Sulfur Metabolism and Sulfur-Containing Amino Acids: IMolecular Effectors. Biochemistry \& Pharmacology: Open Access, 2015. 4(1).

116. Stipanuk, M.H., Sulfur amino acid metabolism: Pathways for production and removal of homocysteine and cysteine. Annual Review of Nutrition, 2004. 24: p. 539-577.

117. Leustek, T., et al., Pathways and regulation of sulfur metabolism revealed through molecular and genetic studies. Annual Review of Plant Physiology and Plant Molecular Biology, 2000. 51: p. 141-165.

118. Vickerman, J.C. and I.S. Gilmore, Surface Analysis - The Principal Techniques. 2009.

119. Butz, T., et al., The Leipzig high-energy ion nanoprobe: A report on first results. Nuclear Instruments \& Methods in Physics Research Section B-Beam Interactions with Materials and Atoms, 2000. 161: p. 323-327.

120. Spemann, D., et al., Materials analysis and modification at LIPSION - Present state and future developments. Nuclear Instruments \& Methods in Physics Research Section B-Beam Interactions with Materials and Atoms, 2011. 269(20): p. 2175-2179.

121. Mulware, S.J., et al., Efficiency calibration of an HPGe X-ray detector for quantitative PIXE analysis. Nuclear Instruments \& Methods in Physics Research Section B-Beam Interactions with Materials and Atoms, 2014. 332: p. 95-98.

122. Booth, A., et al., Freshwater dispersion stability of PAA-stabilised-cerium-oxide nanoparticles and toxicity towards Pseudokirchneriella subcapitata. Science of the Total Environment, 2015. 505: p. 596-605.

123. Tentschert, J., et al., TOF-SIMS analysis of cell membrane changes in functional impaired human macrophages upon nanosilver treatment. Surface and Interface Analysis, 2013. 45(1): p. 483-485.

124. Jungnickel, H., et al., Application of TOF-SIMS with chemometrics to discriminate between four different yeast strains from the species Candida glabrata and Saccharomyces cerevisiae. Analytical Chemistry, 2005. 77(6): p. 1740-1745.

125. Wilcoxon, F., Individual Comparisons by Ranking Methods. Biometrics Bulletin, 1945. 1(6): p. $80-83$.

126. Mann, H.B. and D.R. Whitney, On a Test of Whether one of Two Random Variables is Stochastically Larger than the Other. The Annals of Mathematical Statistics, 1947. 18(1): p. 50-60.

127. Kruskal, W.H. and W.A. Wallis, Use of Ranks in One-Criterion Variance Analysis. Journal of the American Statistical Association, 1952. 47(260): p. 583-621.

128. Dunn, O.J., Estimation of the Means of Dependent Variables. The Annals of Mathematical Statistics, 1958. 29(4): p. 1095-1111. 
Supporting Information

Simultaneous Quantification and Visualization of Titanium Dioxide Nanomaterial Uptake at Single Cell Level in an In Vitro Model of the Human Small Intestine

Thomas Meyer*, Tom Venus, Holger Sieg, Linda Böhmert, Birgitta M. Kunz, Benjamin Krause, Pegah Jalili, Kevin Hogeveen, Soizic Chevance, Fabienne Gauffre, Agnes Burel, Harald Jungnickel, Jutta Tentschert, Peter Laux, Andreas Luch, Albert Braeuning, Alfonso Lampen, Valerie Fessard, Jan Meijer, Irina Estrela-Lopis*

S 1. Semi quantitative analyses of identified proteins in the NM corona compared to the protein composition of the cell culture medium containing FBS.

\begin{tabular}{|c|c|c|}
\hline Bovine Protein & NM103 & NM104 \\
\hline Albumin & - & - \\
\hline$\beta$-actin & + & - \\
\hline Apolopoprotein A-1 & - & - \\
\hline $\begin{array}{l}\text { Alpha-1-antitrypsin homolog } \\
\text { protein }\end{array}$ & + & + \\
\hline Plasminogen & $+/-$ & ++ \\
\hline $\begin{array}{l}\text { Iron export } \mathrm{ABC} \text { transporter } \\
\text { ATPase }\end{array}$ & -- & - \\
\hline Ovotransferrin-like protein & -- & -- \\
\hline Tetranection & + & + \\
\hline Vitamin $\mathrm{D}$ binding protein & -- & - \\
\hline $\begin{array}{l}\text { Solute carrier family } 25 \\
\text { member } 6\end{array}$ & -- & -- \\
\hline Cytochrome oxidase subunit 3 & $+/-$ & $+/-$ \\
\hline
\end{tabular}

+ Enriched; + + enriched, not detectable on medium control gel; - reduced; - - reduced, not detectable; $+/$ - no changes compared to medium control gel. 
A

Mean aggregate areas

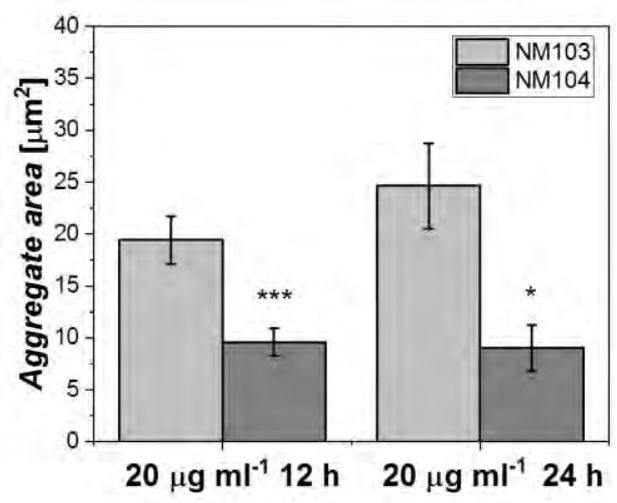

B $20 \mu \mathrm{g} \mathrm{ml}^{-1} 12 \mathrm{~h}$

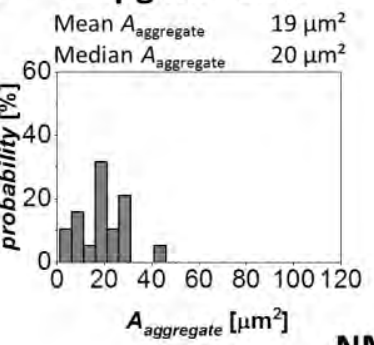

$A_{\text {aggregate }}\left[\mu \mathrm{m}^{2}\right]$

$20 \mu \mathrm{g} \mathrm{ml}^{-1} 12 \mathrm{~h}$

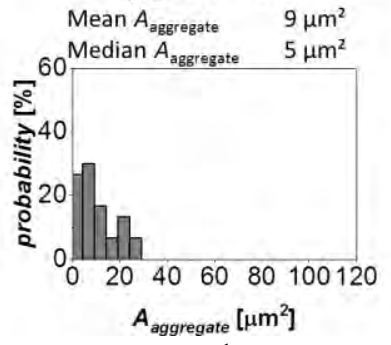

NM103
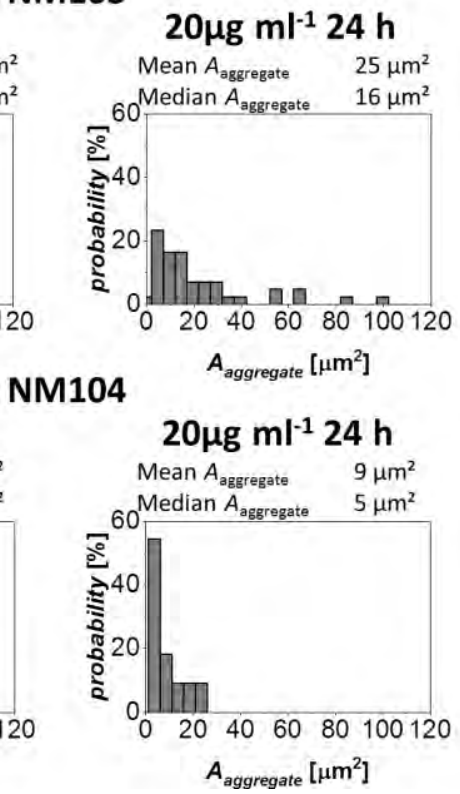

S 2. Mean aggregate size of NM103 and NM104 found for $20 \mu \mathrm{g} \mathrm{ml}^{-1}$ for 12 and $24 \mathrm{~h}$ (A) Number of titanium aggregates over cellular populations. Exposure of $20 \mu \mathrm{g} \mathrm{ml}^{-1} \mathrm{TiO}_{2} \mathrm{NM} 03$ vs NM104 over 12 and $24 \mathrm{~h}$ (B). Error bars display the standard error of the mean.

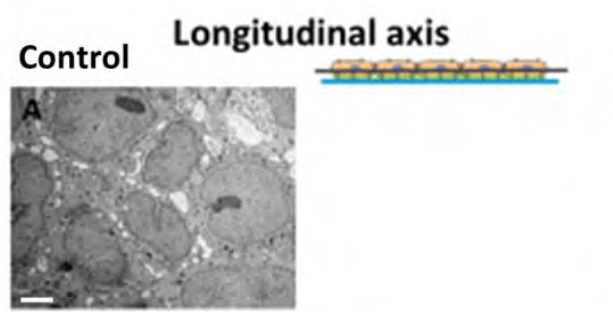

NM103 $128 \mu \mathrm{g} \mathrm{ml}^{-1} 24 \mathrm{~h}$
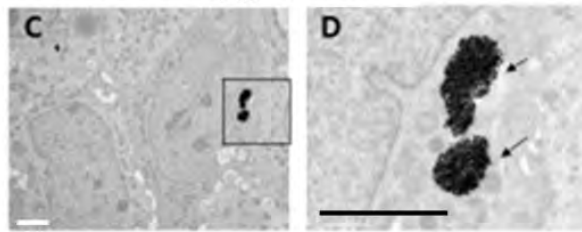

NM104 $128 \mu \mathrm{g} \mathrm{ml}^{-1} 24 \mathrm{~h}$
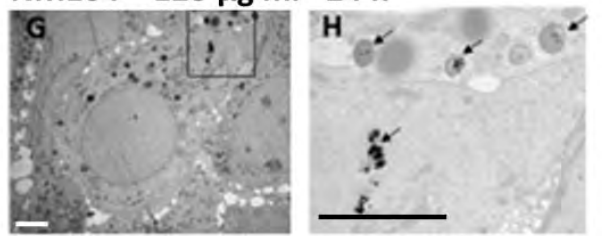

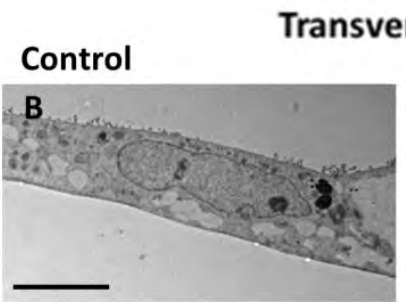

NM103 $128 \mu \mathrm{g} \mathrm{ml}^{-1} 24 \mathrm{~h}$
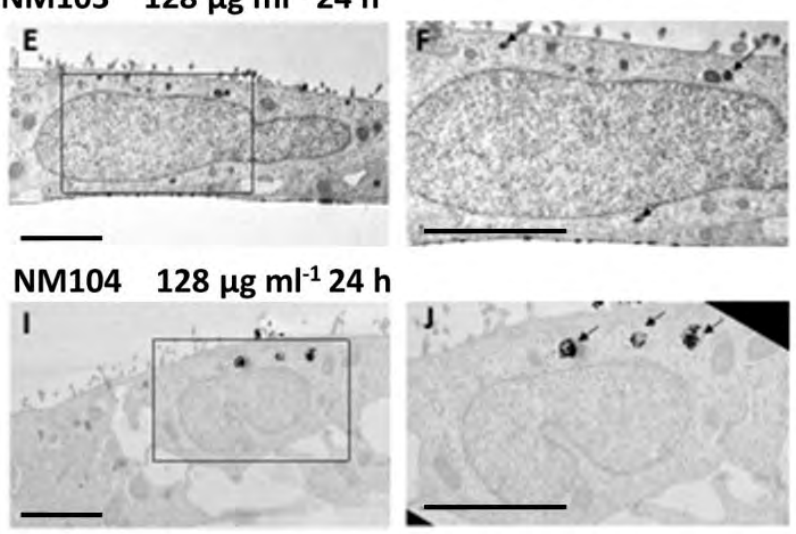

S 3. TEM images of Caco- 2 cells sectioned in two different axes (longitudinal and transversal). Controls cells (A and B) and cells exposed to $128 \mu \mathrm{g} \mathrm{ml}^{-1} \mathrm{TiO}_{2} \mathrm{NM} 103$ (C, D, E, F) and NM 104 for $24 \mathrm{~h}$ (G, H, I, J) are shown. Images D, F, H and J are magnifications of the squares outlined areas in the images $\mathrm{C}, \mathrm{E}, \mathrm{G}$ and I respectively. The black arrows in image $\mathrm{H}$ mark NMs which are entrapped within vesicles. Scale bar: $3 \mu \mathrm{m}$.

Differentiated Caco-2 cells were exposed to $128 \mu \mathrm{g} \mathrm{ml}^{-1} \mathrm{TiO}_{2} \mathrm{NM}$ over $24 \mathrm{~h} .80 \mathrm{~nm}$ sections of the cellular monolayer in the two perpendicular planes, longitudinal (x-y) and transversal (x-z), were prepared for a comprehensive TEM study. 200 cells in longitudinal axis and 50 cells in transversal axis were analyzed for each experiment. The images in $\mathbf{S} \mathbf{3}$ show examples of cellular translocation of NM103 and NM104 particles in enterocytes. Inside the Caco-2 cells $\mathrm{TiO}_{2} \mathrm{NMs}$ were agglomerated as large dense clusters especially for NM103 (S 3 D, black arrows). It was shown that the main pathway 
of NM internalization is endocytosis via recent endosomes, late endosomes and lysosomes.[1] Beside aggregates $\mathrm{TiO}_{2} \mathrm{NMs}$ were also found as small spots inside vesicles, which likely represent endosomes or lysosomes ( $\mathrm{S} 3 \mathrm{H}$, black arrows). Titanium dioxide particles are preferentially found in the top face of the cell but were also detected in the bottom side (S 3 E, F, I and J).

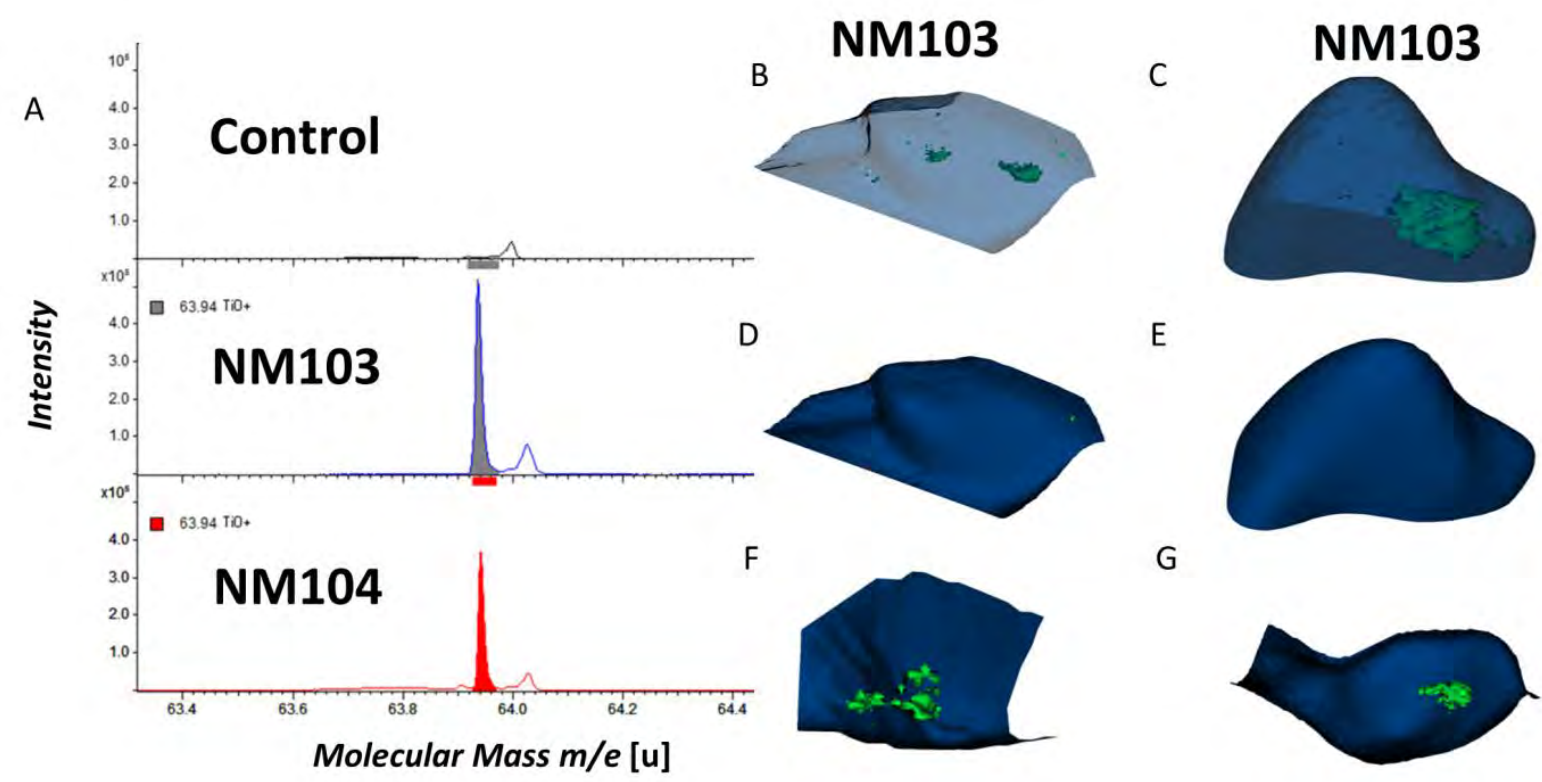

S 4. ToF-SIMS mass spectra (positive mode), showing the titanium oxide peak $\mathrm{TiO}^{+}$in grey (NM-103) and in red color (NM-104) at m/e $63.94 \mathrm{u}$ from cells exposed with $\mathrm{TiO}_{2} \mathrm{NMs}(\mathrm{A})$. Ion reconstruction of a 3D depth profile $(20 \mu \mathrm{m} \times 15 \mu \mathrm{m} \times 3 \mu \mathrm{m})$ of a single Caco-2 cells, which were exposed to NM103 (B, D and F) and $\mathrm{NM} 104 \mathrm{TiO}_{2}(\mathrm{C}, \mathrm{E}$ and $\mathrm{G})$. $\mathrm{B}$ and $\mathrm{C}$ show images of the cells, depicted as translucent blue with $\mathrm{NM}$ aggregates in green color. D and $\mathrm{E}$ visualize the cell outline in solid blue reconstructed from the $\mathrm{C}_{3} \mathrm{H}_{8} \mathrm{~N}^{+}$signal from phosphatidylcholine. E and $\mathrm{F}$ show the cell outline with the lower membrane open. NM aggregates are shown in green color. The cell membrane is visualized in solid blue reconstructed from the $\mathrm{C} 3 \mathrm{H} 8 \mathrm{~N}+$ signal from phosphatidylcholine. For better visualization the cells are depicted upside down.

ToF-SIMS was applied to visualize NMs in cells at an exposure of $47.5 \mu \mathrm{g} \mathrm{ml}^{-1}$ over $24 \mathrm{~h}$ for NM103 and NM104. S 4 A shows TOF-SIMS mass spectra (positive mode) of $\mathrm{TiO}_{2}$ treated cells. The titanium oxide $\left(\mathrm{TiO}^{+}\right)$peak at $m / e=63.94$ was detected clearly for both $\mathrm{TiO}_{2} \mathrm{NMs}$. The $3 \mathrm{D}$ ToF-SIMS reconstruction of single cells indicates unambiguously the intracellular presence of $\mathrm{TiO}_{2}$ nanomaterials. The cells take up both $\mathrm{TiO}_{2}$ nanomaterials, the hydrophobic NM103 (S 4 B, D) and the hydrophilic NM104 (S 4 C, E). Ion reconstruction of a 3D depth profile $(20 \mu \mathrm{m}$ x $15 \mu \mathrm{m} \times 3 \mu \mathrm{m})$ of a single treated Caco-2 cell shows a 3D image of the cell, depicted as translucent blue with $\mathrm{TiO}_{2}$ in green color. The cell boundary was reconstructed from the $\mathrm{C}_{3} \mathrm{H}_{8} \mathrm{~N}^{+}$signal of phosphatidylcholine, which is a main compound of the cell membrane. The hydrophobic and hydrophilic NM aggregates have been found to be internalized. Some of NM103 was found in contact with the cell membrane (S 4). 


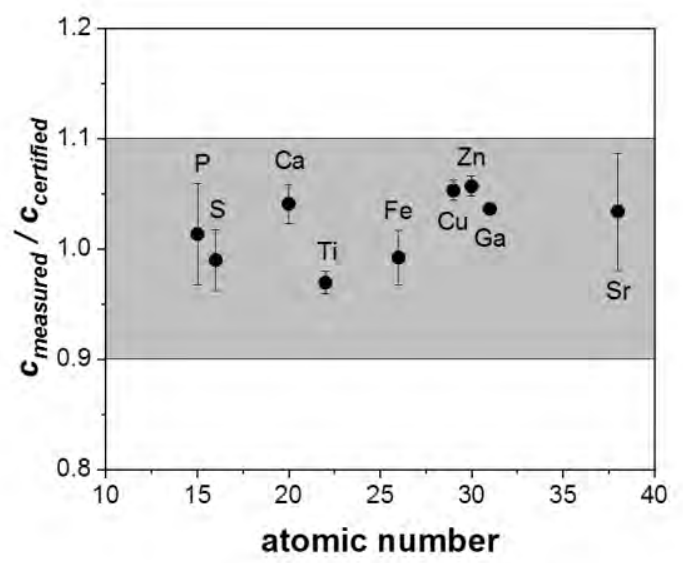

S 5. Verification of PIXE element quantification performed with element standards of Astimex Standards Ldt (Serial EPX1 SPEC 25-53+FC). The measured concentration was compared to the certified concentration given by the producer. The grey box marks a $\pm 10 \%$ range of tolerance. The error bars mark the standard error of the mean.

\section{NM103}
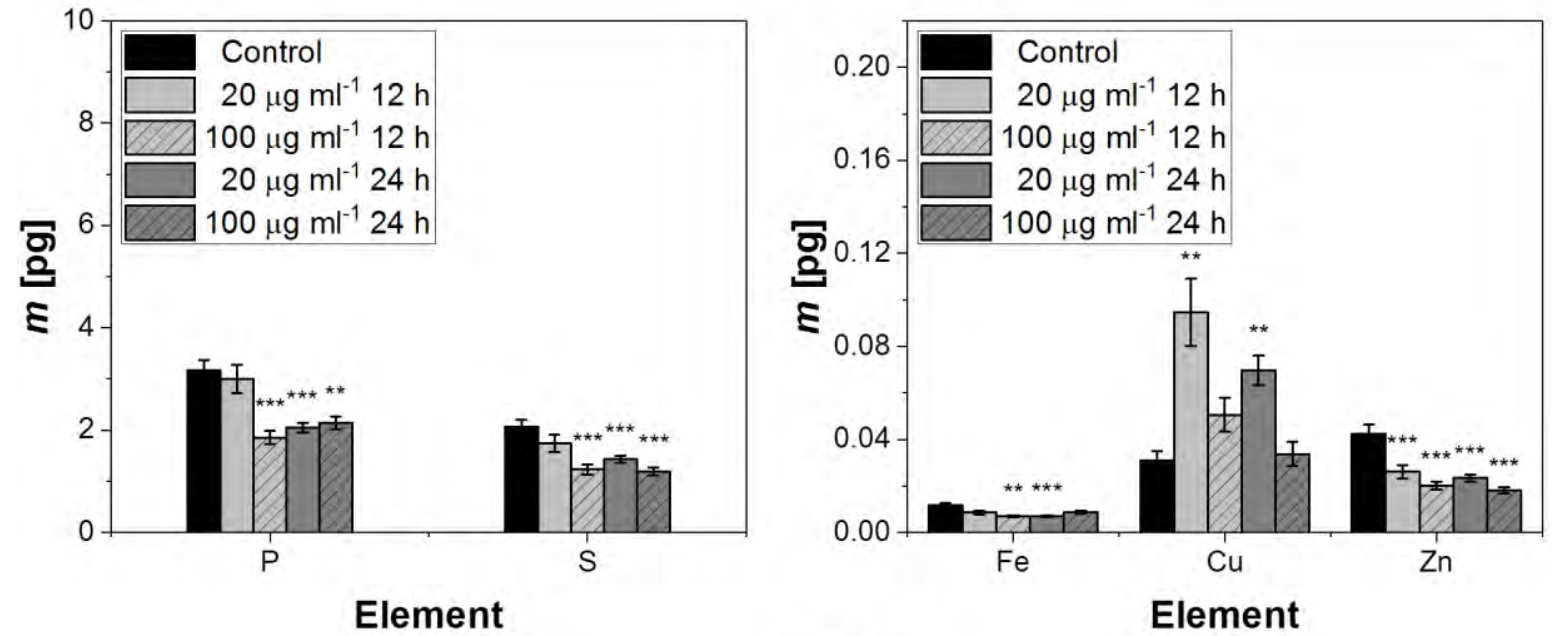

\section{NM104}

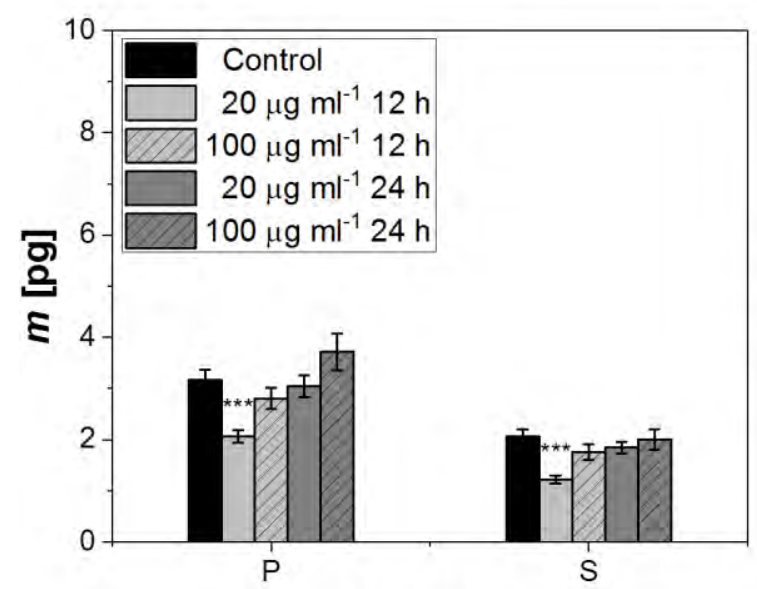

Element

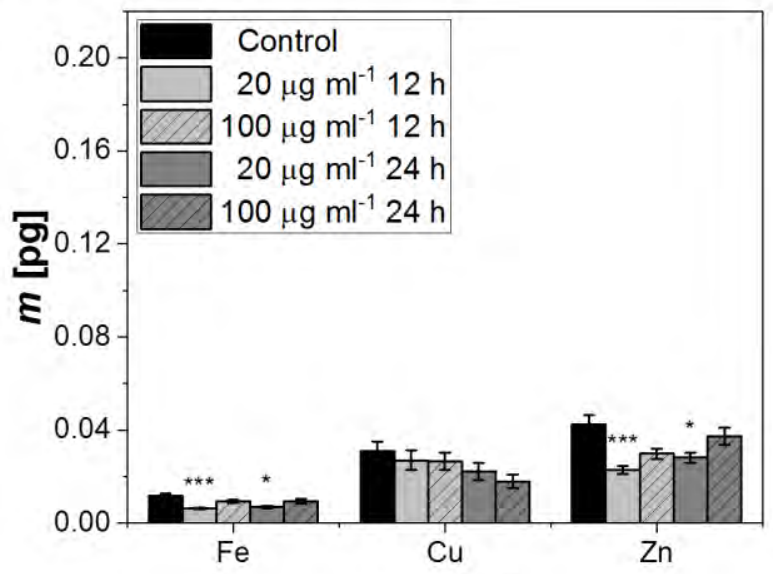

Element

S 6. Quantification of element content in Caco-2 cells exposed to hydrophobic NM103 or hydrophilic NM104 under different conditions. The determined significance levels refer to the control cells. $* \mathrm{P}<0.05 ; * * \mathrm{P}<0.01$; $* * * \mathrm{P}<0.001$. 


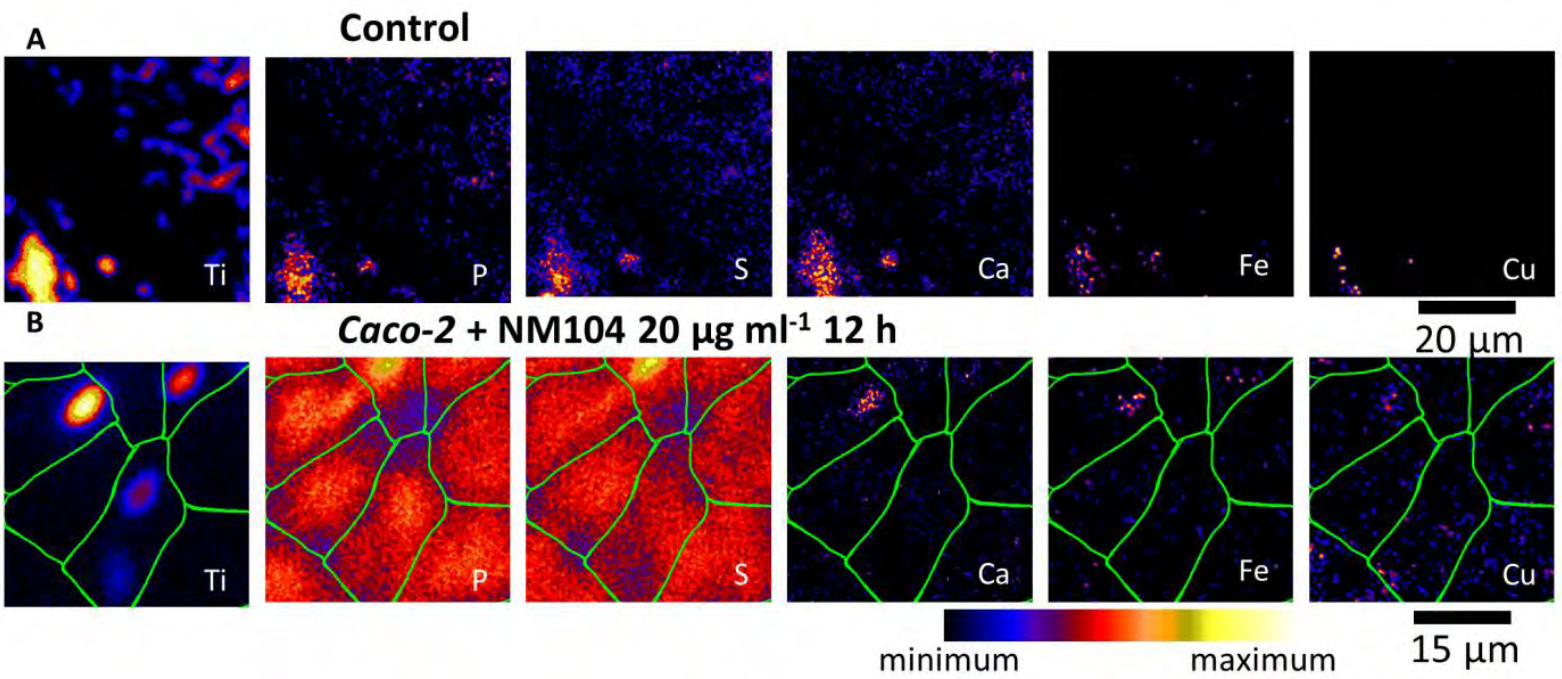

S 7. (A) $\mu \mathrm{PIXE}$ element maps of $\mathrm{TiO}_{2} \mathrm{NM} 104$ in DMEM medium before exposure to cells (control) and (B) Caco-2 cells exposed to $20 \mu \mathrm{g} \mathrm{ml}^{-1} \mathrm{TiO}_{2} \mathrm{NM} 04$ over $12 \mathrm{~h}$.

[1] N. Oh, J. H. Park, Int J Nanomed 2014, 9, 51. 